SAND79-1674

Unlimited Release

Printed April 1980
Distribution

Category UC-35, 37

\title{
PUFF TOO: A RESIDUAL STRESS EXPERIMENT
}

Carl W. Saith

Experiments Planning Division 1112

Sand za Laboratories

Albuquerque, NM 87185

\begin{abstract}
Following the pasage of the dynamic effects in a contained explosive detonation, there remains a strong compressive stress field in the material about the cavity. In this experiment, $454-\mathrm{kg}(1000$ 1b) sphere of high explosive was detonated in saturated ash fall tuff. Instrumentation mesaured peak stresses over the range of 0.1 to $6.0 \mathrm{GPa}$ ( 1 to $6 \mathrm{kbar}$ ) and the complete stress-time waveform, including the so-called residual stresa, at the 0.1 GPa (1 kbar) peak stress range. Mineback revealed detonation-induced fractures and fractures induced by postevent work.
\end{abstract}





\section{CONTENTS}

SURPARY

Int roduction

The Experiment

Location end Enviroment

Material Properties

Experiment Details

Gage Data and Discussion

General

60-Ril abar Gages

6-Kilobar Gage

2-Kilobar Gages

Time-of-Arrival Detectors

Fluid-Co:pled Plate Gages

Accelerometera

1-Kilobar Gages in Tuff

47

1-Rilobar Gages in Grout Stemuing

Cavity Pressure Measuremento

Postevent

$6 !$

Fracture Pressure Experiment

Mineback

APPENDIX A - Gage Calibration

APPENDIX B - Computer Code Calculation

APPENDIX C - Correction of Deta Distorted by Mesauring System 


\section{ILLUSTRATIONS}

Figure

1 Uniaxial Strain Tests on Tuff Samples Measured by Terra Tec, Inc

2 Plan View Showing TNT Sphere, Gate Locations, Stemming Dlug, and Fracture Pípes

3 Time of Arrival (Firgt Energy) va Range

4 Measured Peak Stress vo Range

5 Constantan and Manganin Gages 60CR and 60MK

6 Manganin Gages 60MP and 60MR

7 "Dummy Gage" 60NS1

8 Corrected Fluid-Coupled Ytrerbium Gage 6AYFC

9 Fluid-Coupled Ytterbium Gage 6YFC and Fluid-Coupled Lithium Niobate 6BLFC

10 Solid-Coupled Lithium Niobate Gages $6 \mathrm{LH}$ and 6BLH

11 Fluid-Coupled Ytterbium Gage 2CYFC

12 Soliä-Coupled Lithium Niobate Gage 2CLH

13 Time-of-Arrival Detectors $2 \mathrm{~T}$ IS and 2T1B

14 Time-of-Arrival Detectors 2T3S and 2T3B

15 Fluid-Coupled Plate Gages 3FCP, 2FCP, and IFCP

16 Radial Accelerometer lAR2

17 Vertical and Transverse Accelerometers 1 AV2 and IAT2

18 Radial hecelerometer laR!

19 Accelerometers $1 \mathrm{AVI}$ and 1AT1

20 Accelerometer lAR2, Particle Velocity (from 1AR2), and Lithium Niobate Stress Gage 1LH 


\section{ILLUSTRATIONS (cont)}

Figure

21 Fluid-Coupled Lithium Niobate Gage 1DLFC

48

22 Fluid-Coupled Ytterbium Gage IDYFC and Solid-Coupled Lithium Niobate Gage 1DLH

23 Traxial Yeterbium Gage With Elements IEYGl, IEYG2, and IEYG3

24 Corrected Version of IEYGl Gage Element With Time Measured From TOA

25 Corrected Version of 1EYG2 Gage clement with Time Measured From TOA

26 Fluid-Coupled Ytterbium Gage 1YFC and Solid-Coupled Lithium Niobate Gage ILH

27 Lithium Niobate Triaxial Gage With Elements 1LD1 and ILD2 53

28 Triaxial Yterbium Gage with Elements 1YG1, IYG2, and 1YG3 54

29 Corrected Version of Element 1YG1 With Time Measured From TOA

30 Cavity Pressure From Events RS-5, RS-6, and RS-9 58

3 I Cavity Pressure From Event RS-4 (64 lb) 58

32 Cavity Pressure From Event RS-3 (0 to 5 s) 59

33 Cavity Pressure From Event RS-3 (0 to 70 6) 60

34 Locations of Postshot Nitrogen and Water Fractures 63

35 Vertical and Plan Views of Cavity 66

36 Plan View of Mineback Showing Zones of Shear Surface, Onion Skin Fractures, and Soft Tuff

B-1 CHART D Calculation - Stress vg Digtance at $10 \mathrm{~ms}$

B-2 Calculated and Measured Stresses vo Time at $133 \mathrm{~cm} 75$

B-3 Calculated and Measured Stresses vs Time at $290 \mathrm{~cm} 76$

B-4 Calculated and Measured Stresses vs Time at $419 \mathrm{~cm} \quad 77$ 


\section{ILLUSTRATIONS (cont)}

Figure

C-1 Data From Gage 6AYFC as Recorded (Diatorted by Short Time Constant)

C-2 Unit Step Regponge of Signal Conditioning

C-3 Data Frod Gage ó YYC Corrected for Tranaient Diatortion

\section{TABLES}

Table

1 Material Properties (Holmes and Narver) 14

2 Material Propertie日 (Terra Tec, Inc) 14

3 Gage Types and Locationg 18

4 Data Recovery 21

5 Fracture Pipe Data 63 
SUMMARY

PUFF TOO was a nuclear containment-related experiment in wich a 454-kg (1000-1b) high explosiye was detonated in saturated tuff in G Tunnel at NTS. Currently available prototype atresa gages were fielded to assess their ability to measure the complete stress-time profile; particular emphasis wa flaced on measuring the late-tique reaidual stress. Mineback was performed to examine gages, cavity details, and fractures which were detonation-related or induced after the event.

In tuft at the 1-kbar peak dynamic range, three atress gages with two types of sensors ( 1 ithium niobate and ytterbium) measured the full stresstime profile and showed an average residual stress of $0.25 \mathrm{kbar}$. In the grout stemming plug at the ame range, seven sensing elements with three types of sensors (lithiwo niobate, ytterbium, and a fluid-coupled plate) measured residual stresa; these values cluster about $0.19 \mathrm{kbar}$. With in creasirg peak stress levels, proportionally shorter recording times were obtained; at the 60-kbar level only the peak values are credible. We believe that the ability to measure residual atress is currently limited by survival of the gage package and cable.

Al though we measured a residusl atress at the l-kbar level, it is not clear which atress component--mean, radial, or some intermediate value-was measured. Cslibration data are available only for the one-dimension atra:n and hydrostatic loadinga; at the 1-kbar level we wust take into account the triaxial state of stress wich loads these gages. The triaxial stresa development gage and its background work is a stact on this problem.

Work performed 2.5 hr after the detonation showed the presence of cavity gas 3.5 cavity radii $(387 \mathrm{~cm})$ from the original charge center. Specific locations in the residual stress field vere pressurized and 
fractured with nitrogen; fracture pressures indicate the approximate dependence of the residual atress field with range.

Mineback on the PUFF TOO event revealed alickenside (sheared) surfaca in che tuff approximately radial to the charge and parallel to the steming plug. The surface started 1,5 cavity radii $(165 \mathrm{~cm})$ from the charge center and extended to $4.3 \mathrm{cavity}$ radii $(463 \mathrm{~cm})$. We believe that this sheared surface was the path for the cavity gas observed at $387 \mathrm{~cm}$. We suggest that the slickenside surface is related to stress relief around the ingtallation drift.

Examination of gages recovered during mineback allowed us to verify proper gage operation and helped us to explain anomalous gage records. The directions of the postevent fractures were obtained and provided information related to the components of the residual atress field. The cavity was elongated in the approximate direction of the steming plug and showed maximum and minimum horizontal radii of $125 \mathrm{~cm}(4 \mathrm{ft})$ and $100 \mathrm{~cm}$ $(3.5 \mathrm{ft})$. The averaged radius was $108.4 \mathrm{~cm}(3.56 \mathrm{ft})$.

A pre-event computer code calculation had been made for design purposes. We see reasonable agreement with field measurements in the peak dynamic and residual time frames and disagreement at intermediate times. Predicted cavity radius was $80 \mathrm{~cm}$, which may be compared with the averaged observed value of $108.4 \mathrm{~cm}$. Predicted cavity presaure of $0.55 \mathrm{kbar}$ is close to the larger $(0.52 \mathrm{kbar})$ of the two cavity pressure measurements. 
Introduction

A major role in the containment of underground nuclear detonations is credited to a late-time detonation effect called the residual stress field. If a calculation of the nuclear event is continued to late times, it shows an elastic rebound of material in the far-field which loads the plastically-deformed material closer to the cavity. Loaded by the cavity pressure on one side and by the inward converging material on the other side, this near-field region experiences strong compressive stresses which persigt as long as the calculation is continued. This residual stress field is able to contain cavity pressures.

Calculations show a residual hoop (or tangential) stress whose peak is physically close to the cavity and has a maximum amplitude of about $1 \mathrm{kbar}$. This stress decays with distance, sometimes shows negative values, and then approaches in-situ value about five cavity radii from the charge center. The radial residual stress, on the other hand, rises to a peak at about 1.5 cavity radii, shows an amplitude slightly lower than the maximum hoop stress, and decays to the in-aitu value. (Some calculations show detail in the decaying part of these fields.) Calculations of highexplosive events show that these residual fields are able to contain the approximately 0.5-kbar pressure found in the cavity.

Interest in this effect is not confined to nuclear containment because the residual stress field is a general geomechanical effect resulting when confined explosions interact with the solid. An old prectice in oil fields was to detonate explosives in \& well in an attempt to enhance production. Current knowledge of the residual stress effect, however, shows that flow of oil into the well may actually be inhibited, at least 
until the residual field decays. Therefore, any energy recovery that involves exploaives must take inco account thi reaidual atress effect.

Gage measurement of reaidual atress fields are difficult since the instrumentation must ourvive the pasage of the dynamic effects. Typically the dynamic amplitudes are 5 to 10 times larger than the residual gtregs amplitude. For example, to measure $1 \mathrm{kbar}$ of reaidual stress, a gage mut survive the $10 \mathrm{kbars}$ of dynamic atresa and still retain a linear, or recoverable, cal ibration.

Active gage measurements of the complete stress vs time history are valuable for comparioon with a calculation of the event. Agreement between data and calculation would suggeat that one has accounted for the major proceses involved and has modeled the phenomenon correctly.

We had several objectives in this 454-kg (1000-1b) high-explosive experiment (PUFF TOO). ${ }^{*}$ The primary one was to measure, with currently available gages, the complete stresa-time waveforms, with particular caphayia on the late time or reaidual stress regime. Another objective was to measure aid examine some of the phenomenology of a high explosive detonation. The third objective was to provide test bed for gage development work.

The next section presents the general details of the experiment. Subsequenty we display the measured waveforms. Finally, we discuss postevent and the mineback work. Appendicer discuss current gage measurement problema, detail a pre-event design calculation of the detonation process, and describe a waveform correction technique.

\footnotetext{
*This experiment is al ao known as RS3
} 


\section{The Experiment}

\section{Location and Envirozment}

We fielded PUFF too in G Iunnel, Rainier Mesa, Nevada Teat Site (NTS) in saturated ashfall tuff. The experiment drift was an extension of another drift, designated HFS20; these drifts are located at construction station $25+00$ in the main $G$ Iunnel drift (U12g.10M.D.B.P.). Here the vertical distance to the mesa surface is $420 \mathrm{~m}$. Before PUFF TOO, hydroulic fracture measurements were made in the area and analysis yielded the following values for the in-situ stress:

- Maximum horizontal stress: $6.41 \mathrm{MPa}\left(930 \mathrm{1b} / \mathrm{in}^{2}\right)$, oriented $\mathrm{N} 42^{\circ} \mathrm{E}$

- Minimum horizontal stress: $5.34 \mathrm{MPa}\left(7751 \mathrm{~b} / \mathrm{in}^{2}\right)$

- Vertical stress $8.76 \mathrm{MPa}\left(1270 \mathrm{lb} / \mathrm{in}^{2}\right)$

\section{Material Properties}

The geologic host for PUFF TOO was zeolitized ashfall tuff in Bed 4 of the bedded sequence encountered in G Tunnel. Seven samples from the mined emplacement drift were sent to Holmes and Narver (HóN) Material Testing Laboratory at NIS, and twc samples were sent to Terra Tec, Inc, at Salt Lake City. The HoN values and standsrd deviations (SD) are listed in Table 1.

Along with uniaxisl strain testa, Terra Tec also messured material properties on one sample taken at $22.25 \mathrm{~m}(73 \mathrm{ft})$ from the start of rhe drift and on one sample from $36.88 \mathrm{~m}(121 \mathrm{ft})$. Table 2 lists their values.

Figure 1 shows the results of Terra Tec ${ }^{2}$ s uniaxial strain tegta on thege two sanples. 
Table 1

Material Properties (Holmes and Marver)

\begin{tabular}{|c|c|c|}
\hline Properties & Average Valued & $\begin{array}{l}\text { Standard } \\
\text { Deviarion } \\
\end{array}$ \\
\hline Unconfined crushing strengch & $9.24 \mathrm{MPa}\left(1340 \mathrm{lb} / \mathrm{in}^{2}\right)$ & $3.3 \mathrm{MPa}$ \\
\hline $\begin{array}{l}\text { Sanic pulse compressive } \\
\text { velocity }\end{array}$ & $2.16 \mathrm{~km} / \mathrm{s}$ & $0.17 \mathrm{~km} / \mathrm{s}$ \\
\hline Shear velocity & $1.08 \mathrm{~km} / \mathrm{s}$ & $0.19 \mathrm{~km} / \mathrm{s}$ \\
\hline \multicolumn{3}{|l|}{ Density } \\
\hline Natural state & $1.92 \mathrm{Mg} / \mathrm{m}^{3}$ & $0.308 \mathrm{Mg} / \mathrm{m}^{3}$ \\
\hline Dry & $1.57 \mathrm{Mg} / \mathrm{m}^{3}$ & $0.054 \mathrm{Mg} / \mathrm{s}^{3}$ \\
\hline Grain & $2,50 \mathrm{Mg} / \mathrm{m}^{3}$ & $0.024 \mathrm{~kg} / \mathrm{m}^{3}$ \\
\hline $\begin{array}{l}\text { Moiature content, Datural } \\
\text { basis }\end{array}$ & $17.8 \%$ & 1.37 \\
\hline Porcsity & $36.8 \%$ & $2.1 \%$ \\
\hline Saturacion & $92.7 \%$ & $1.9 \%$ \\
\hline
\end{tabular}

Teble 2

Material Properties (Terra Tec, Inc)

\section{Properties}

Density $\left(\mathrm{Mg} / \mathrm{m}^{3}\right)$
As received
Dry
Grain
Water by veight ( $\%)$
Porosity ( $\%)$
Saturation
Measured permanent compaction ( $\%)$
Ultrsaonic velocity (km/s)
Longitudina]
Shear

Values at Stated Distance
22.25 m

$\begin{array}{rr}1.90 & 1.76 \\ 1.53 & 2.48 \\ 2.48 & 2.43 \\ 19.70 & 25.20 \\ 38.50 & 45.60 \\ 97.30 & 97.40 \\ 1.50 & 1.90\end{array}$

2.81

2.73

1.27

1.16 

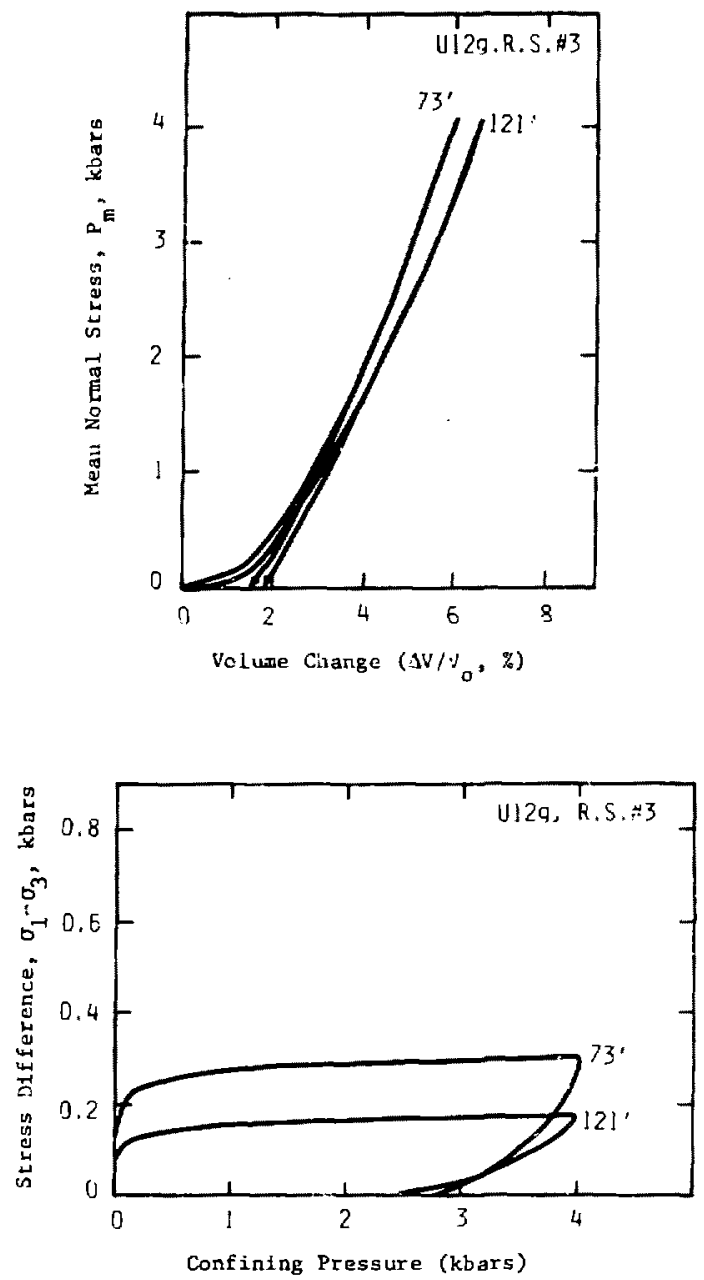

Figure 1. Uniaxial Strain Test on Tuff Samples Measured by Terra Tec, Inc 
Containment of PUFF TOO was required if we were to obtain merningful meas!rements of residusl atress and cavity pressure. We stemed che first 16 m of the $41-m$ emplacement drift with a high-strength grou: (HAHSGC); the rest of the drift, including the volume around the high-explosive sphere, was stemed with a grout (GTMG7) designed to natch the shear strength of the tuff. Originally designed for the MIGHTY BPLU structures experiment, this ME8-11 grout recipe was modified to be used in omall volumes and to achieve about in 8.3-MPa (1200-1b/in $\left.{ }^{2}\right)$ unconfined crush strength in 12 days of curing. Samples of thio steming grout, cured for 14 days, showed a denaity of $2 \mathrm{Mg} / \mathrm{m}^{3}$, a sonic velocity of about $3 \mathrm{~km} / \mathrm{a}$ $(10,000 \mathrm{ft} / \mathrm{s})$, and an unconfined crush strength of $\mathrm{i.2}$ to $8.75 \mathrm{MPa}(1190$ to $1270 \mathrm{lb} / \mathrm{in}^{2}$ ).

\section{Experiment Details}

We emplaced the PUFF TOO expariment in a wined drift that wa $41 \mathrm{~m}$ long, $1.8 \mathrm{~m} \mathrm{high}$, and $1.2 \mathrm{~m}$ wide $(135 \times 6 \times 4 \mathrm{ft})$; the initial design called for a 36 m (120-ft) emplacement drift but natural fracturea were encountered at this distance. As shown in Figure 2, the 1.2- $\times 1.8-\mathrm{m}$ drift tapers down to slightly larger than the size of the high explosive sphere, thereby minimizing the amount of grout around the sphere and allowing the cavity to grow wostly in tuff. The explosive was a cast TNT sphere with a diameter of $81.92 \mathrm{~cm}(32.25 \mathrm{in})$ and a $\mathrm{mags}$ of $453.6 \mathrm{~kg}$ ( $10001 \mathrm{~b})$. Inaide the INT was a $25.4-\mathrm{cin}(10-\mathrm{in})$ diameter pentolite booster which was center-detonated with an exploding bridgewire device. The so-called tuff gages were inserted and grouted in $10.2-\mathrm{cm}-(4-i n)$ diameter drilled holes. Aluminum fixtures, bolted to the floor of the drift, supported the gages in the grout stemming plug. Four high-strength steel pipes terminated in the tuff at varying diutances from the charge center. After the sinot, we pumped nitrogen into these pipes to measure the pressure needed to overcome the residual stress. We fielded numerous gages : a this event, mainly stress gages, with emphasis on those that offered the possibility of measuring residual stress. We fielded other gages wich were in various stages of development because the event offered a point source explosion which was essentially free of reflecting boundaries. 


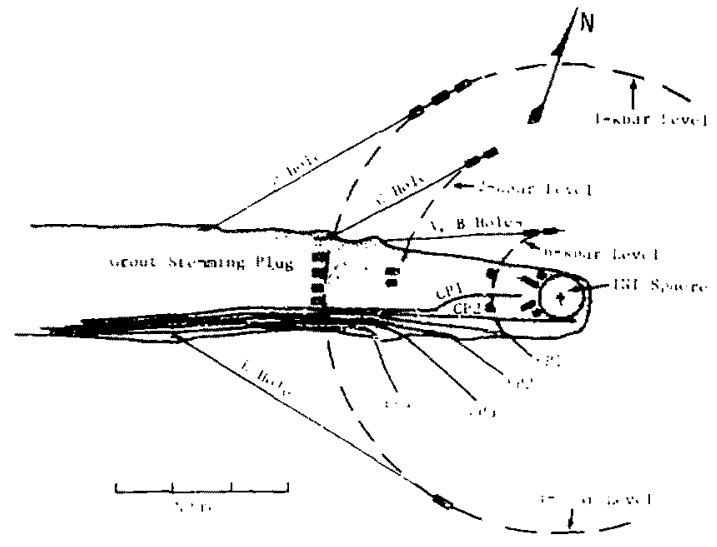

Figure 2. Plan View Showing TNT Sphere, Gage Locations, Steming P1ug, and Fracture Pipes

The principal gages fielded to measure stress-time waveforma vere paddle-shaped, about $7 \mathrm{~cm}$ wide and $15 \mathrm{~cm}$ long. Piezoreaistive, and piezoelectric transducers (ytterbium and lithium niobate) were used in the paddles. Some of the gages used a thin fluid bath for coupling around the sensor. For ytterbium this fluid coupling provided a hydrostatic loading, eliminating a hystersis problem; for lithium niobate the fluid coupling minimizes shear-atress loading on the cryatal, probably enhancing the survival of this brittle material.

When gages are used at stresses that are large when compared with material strengtha of the transducer, the material deforms in onedimensional otrain; appropriate calibration data are available for this case. Whell used below $\sim 2 \mathrm{kbar}$, the effects of macerial strength become important. We must then account for triaxial atresses experienced by the gage and one-dimenaional calibrations may not be appropriate. This problem and the specific calibrations used to reduce the data are discussed in Appendix A. Table 3 gives gage locations, gage type, and host material. 
Table 3

Gage Types and Locations

\begin{tabular}{|c|c|c|c|c|}
\hline $\begin{array}{l}\text { Gage } \\
\text { Type }\end{array}$ & $\begin{array}{l}\text { Distan } \\
\text { Workin } \\
\text { (co) }\end{array}$ & $\begin{array}{r}\text { From } \\
\text { Point } \\
(f t)\end{array}$ & $\begin{array}{c}\text { Host } \\
\text { Material }\end{array}$ & Notes \\
\hline $6 \mathrm{CMK}$ & 51.1 & 1.68 & Grout & End-loaded mang :iln element \\
\hline $50 \mathrm{CK}$ & $5 L \cdot 1$ & 1.68 & Grout & End-loaded constantan element \\
\hline $60 \mathrm{MP}$ & 51.1 & 1.68 & Grout & Manganin element in C7 epoxy \\
\hline 60YR & 51.1 & 1.68 & Grout & Manganin element in RFN epoxy \\
\hline $69 \mathrm{LFC}$ & 140.3 & 4.60 & Tuf f & Fluid-coupled lithium niobate \\
\hline GBLH & 132.8 & 4.36 & TufE & Solid-coupled lithium niobate \\
\hline GAYFC & 132.3 & 4.34 & Tufe & Fluid-coupled yttertitum \\
\hline 6Ltll & $1<0.3$ & 3.95 & Grout & Solid-coupled Ithium niobate \\
\hline 6YFC & 121.9 & 4.00 & Grout & Flu1d-coupled ytterbium \\
\hline 2CYFC & 286.7 & 9.41 & TuEf & Fluid-coupled yt terbium \\
\hline 2CLH & 284.1 & 9.32 & Tuff & Sol id-coupled Itthium niobate \\
\hline $3 F C P$ & 184.2 & 6.04 & Grout & Steel-housed Elutd-coupled plate \\
\hline $2 F C P$ & 287.3 & 9.43 & Grout & Aluminum-housed fluld-coupled plate \\
\hline $2 F C P$ & 418.5 & 13.73 & Gro'st & Aluminum-hoised fluid-coupled plate \\
\hline $\left.\begin{array}{l}2 T 1 S \\
2 T 1 B\end{array}\right\}$ & 269.6 & 8.84 & Grout & $\begin{array}{l}\text { TOA detector, PZT rings } 1-\text { in } \\
\text { diameter }\end{array}$ \\
\hline $\left.\begin{array}{l}2 \mathrm{~T} 3 \mathrm{~B} \\
2 \tau 3 \mathrm{~S}\end{array}\right\}$ & 264.8 & 8.70 & Grout & $\begin{array}{l}\text { TOA detector, PZT rings } 3-\text { in } \\
\text { diameter }\end{array}$ \\
\hline $\left.\begin{array}{l}1 A 2 L \\
1 A T 1 \\
1 A V L\end{array}\right\}$ & 395.3 & 12.97 & Grout & $\begin{array}{l}\text { Triaxial accelerometer package, } \\
\text { epoxy housing }\end{array}$ \\
\hline $\begin{array}{l}\text { LAR2 } \\
\text { LAT2 } \\
\text { IAV2 }\end{array}$ & 395.9 & 12.99 & Grout & $\begin{array}{l}\text { Triaxial accelerometer package, } \\
\text { aluminum housing }\end{array}$ \\
\hline IYEC & 421.8 & 13.84 & Grout & Fluld-coupled ytterblum \\
\hline $1 \mathrm{LH}$ & 4.1 .8 & 13.84 & Grout & Sol 1d-coupled 11thlum niobate \\
\hline $\left.\begin{array}{l}\text { 1LD1 } \\
\text { ILD2 }\end{array}\right\}$ & 407.8 & 13.38 & Grout & $\begin{array}{l}\text { Triaxial stress gage package with } \\
\text { lfthium niobate sensors }\end{array}$ \\
\hline $\left.\begin{array}{l}1 Y G 1 \\
1 Y G 2 \\
1 Y G 3\end{array}\right\}$ & 407.5 & 13.37 & Grout & $\begin{array}{l}\text { Triaxial stress gage package with } \\
\text { ytterbium sensors }\end{array}$ \\
\hline IDLH & 417.3 & 13.69 & Tute & Soltd-coupled lithlum nlobate \\
\hline
\end{tabular}


Table 3 (cont)

\begin{tabular}{|c|c|c|c|}
\hline $\begin{array}{l}\text { Gage } \\
\text { Type } \\
\end{array}$ & $\begin{array}{l}\text { Distance From } \\
\text { Working Point } \\
\text { (cr) (ft) }\end{array}$ & $\begin{array}{c}\text { Hoat } \\
\text { Material }\end{array}$ & Notes \\
\hline IDYFC & 417.0 & Tuff & Fluid-coupled ytterbium \\
\hline IDLFC & 13.74 & Tuff & Fluid-coupled lithium niobate \\
\hline $\begin{array}{l}\text { 1EYG } \\
\text { IEYG2 } \\
\text { IEYG3 }\end{array}$ & 405.4 & Tuff & $\begin{array}{l}\text { Triaxial stresa gage package with } \\
\text { ytterbium gensors }\end{array}$ \\
\hline CPI & $-\infty$ & Grout & Rudial cavity preasure gage \\
\hline GP2 & - & Grout & Tangential cavity presoure gage \\
\hline \multicolumn{4}{|c|}{$\begin{array}{l}\text { Cage power supplies and signal conditioning equipment were located } \\
\text { rground about } 46 \text { w ( } 150 \mathrm{ft} \text { ) from the working point. Ccaxial and } \\
\text { ced shielded pair (TSP) cables carried the signals to a recording } \\
\text { ler at the tunnel portal. Date a:e recorded on two Bell and Howell } \\
\text { to tape machines; output from faut rise-time gages was recorded with } \\
\text {-band electronics and from glower rise-time gages with multiplex } \\
\text { tronics. }\end{array}$} \\
\hline
\end{tabular}

Analog data on the magnetic tape were digitized and filtered at various rates. These ranged from the ampling intervel of $0.2 \mu$ and a low-pass filter of $400 \mathrm{kHz}$ for the 60-kbar gages to a $5.0-\mu \mathrm{s}$ interval and $20 \mathrm{kHz}$ low-pass filtering for the l-kbar gageg.

Gage Data and Discussion

\section{General}

Data recovery on this experiment was good. Of the 44 gage elements, a hook-up error caused the loss of one and improper gignal conditioning distorted recorda from two gage elementa slightly and from three moderately. Gage waveforms are discussed later; here we will show time of arrival (TOA) and peak-stress values as an overview of the data. 
Table 4 presenta gage locations, TOA of the firtt energy, peak atresses, and residual atressed. Over the gtress range of 1 to 60 kbar: moat srrival tinea cluater near a line (Figure 3). The main energy observed on the fluid-coupled plate (PCP) gagea beem to have arrived late. Acceleronecer arrivals are early when compared to atreas-gage arrivals; Accelergneters on other field experiments have encountered this effect. The TOA gagea al oo show early arrivals, Excluding the 60-kbar, TOA, and FCP gages, and accelerometerg a least-oquares fit of the TOA data gives

$$
t(\mathrm{~ms})=0.0041 \mathrm{R}(\mathrm{cm})-0.164
$$

and the observed relocity is $2.45 \mathrm{~km} / \mathrm{s}(8.03 \mathrm{ft} / \mathrm{ms})$. If we consider only the gages in tuff, we observe a mean velocity of $2.43 \mathrm{~km} / \mathrm{s}$; for gages in the grout otemming plug, we see a mean velocity of $2.46 \mathrm{~km} / \mathrm{a}$.

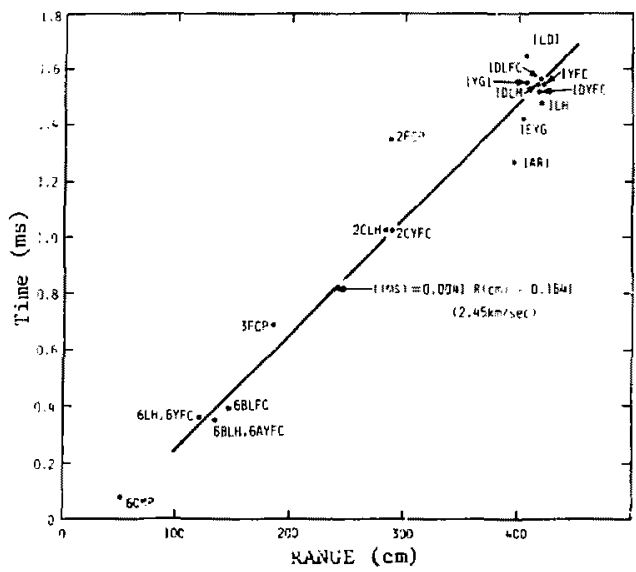

Figure 3, Time of Arrival (First Energy) vs Range 
Table 4

Data Recovery

\begin{tabular}{|c|c|c|c|c|c|c|}
\hline \multirow{2}{*}{$\begin{array}{c}\text { Gage } \\
\text { Stress } \\
\end{array}$} & \multicolumn{2}{|c|}{ Range } & \multirow{2}{*}{$\begin{array}{l}\text { Time of Arrival } \\
\text { (ms) }\end{array}$} & \multirow[t]{2}{*}{$\begin{array}{l}\text { Peak } \\
\text { Stres } \\
\text { (kbar) } \\
\end{array}$} & \multirow[t]{2}{*}{$\begin{array}{c}\text { Res Idual } \\
\text { Stress } \\
\text { (kbar) } \\
\end{array}$} & \multirow[t]{2}{*}{$\begin{array}{c}\text { Peak } \\
\text { Acceleration } \\
\text { (kflo-gravities) }\end{array}$} \\
\hline & - & & & & & \\
\hline $60 \mathrm{MK}$ & 51.1 & 1.68 & $0 . c 855$ & -- & -- & -- \\
\hline GOCK & 51.1 & 1.68 & 0.080 & - & - & - \\
\hline GOMP & 51.1 & 1.68 & 0.080 & 52.00 & -- & -- \\
\hline GOMR & 51.1 & 1.68 & 0.082 & 63.00 & - & -- \\
\hline 6BLFC & 140.3 & 4.60 & $0.390 \pm 0.003$ & -- & -- & - \\
\hline $6 \mathrm{BLH}$ & 132.8 & 4.36 & $0.348 \pm 0.002$ & - & -- & - \\
\hline GAYFC & 232.3 & 4.34 & $0.348 \pm 0.002$ & 7.80 & - & $\rightarrow$ \\
\hline 6LI & 120.3 & 3.95 & $0.357 \pm 0.003$ & -- & $\rightarrow$ & - \\
\hline 6YFC & 121.9 & 4.00 & $0.35 ? \pm 0.003$ & 9.70 & - & -- \\
\hline $2 \mathrm{CYFC}$ & 286.7 & 9.41 & $1.025 \pm 0.005$ & 2.10 & 0.220 & -- \\
\hline 2CLH & 284.1 & 9.32 & $1.025 \pm 0.005$ & -- & -- & -- \\
\hline $3 F C P$ & 184.2 & 6.04 & 0.6900 & -- & -- & -- \\
\hline $2 \mathrm{FCP}$ & 287.3 & 9.43 & 1.27 & 2.80 & -- & -- \\
\hline $1 \mathrm{FCP}$ & 418.5 & 13.73 & $\sim 1.69$ & 0.80 & 0.200 & $\rightarrow$ \\
\hline $\begin{array}{l}2 \mathrm{~T} 1 \mathrm{~S} \\
2 \mathrm{~T} 1 \mathrm{~B}\end{array}$ & 269.6 & B. 84 & 0.82 & -- & $-\infty$ & -- \\
\hline $\begin{array}{l}2 \mathrm{~T} 3 \mathrm{~B} \\
2 \mathrm{~T} 3 \mathrm{~S}\end{array}$ & 264.8 & 8.70 & 0.81 & -- & -- & -- \\
\hline IYFC & 421.8 & 13.84 & $1.550 \pm 0.50$ & 0.60 & c. 200 & -- \\
\hline $1 \mathrm{LH}$ & 421.8 & 13.84 & $1.480 \pm 0.30$ & 0.93 & 0.230 & -- \\
\hline $\begin{array}{l}\text { ILD I } \\
1 \mathrm{LD} 2\end{array}$ & 407.8 & 13.38 & $1.650+0.20$ & $\begin{array}{l}0.52 \\
0.57\end{array}$ & $\begin{array}{l}0.185 \\
0.150\end{array}$ & -- \\
\hline $\begin{array}{l}\text { IYG } 1 \\
1 Y G 2 \\
1 Y G 3\end{array}$ & 407.5 & 13.37 & $\begin{array}{l}1.550+0.05 \\
1.550 \pm 0.10 \\
1.500 \pm 0.10\end{array}$ & $\begin{array}{l}1.24 \\
1.24 \\
1.29\end{array}$ & $\begin{array}{r}-\overline{-} \\
0.16 \\
\because .23\end{array}$ & -- \\
\hline $\begin{array}{l}\text { IDLH } \\
\text { LDYFC } \\
\text { IDLFC }\end{array}$ & $\begin{array}{l}417.3 \\
417.0 \\
418.8\end{array}$ & $\begin{array}{l}13.69 \\
13.68 \\
13.74\end{array}$ & $\begin{array}{l}1.550 \pm 0.05 \\
1.520 \pm 0.02 \\
1.560 \pm 0.02\end{array}$ & $\begin{array}{l}1.60 \\
0.83 \\
1.02\end{array}$ & $\begin{array}{l}0.320 \\
0.240 \\
0.260\end{array}$ & $\begin{array}{l}-- \\
-- \\
--\end{array}$ \\
\hline $\begin{array}{l}\text { IEYG } 1 \\
\text { IEYG } 2 \\
\text { IEYG } 3\end{array}$ & 405.4 & 13.30 & $1.42 \pm 0.020$ & $\begin{array}{l}1.02 \\
1.14 \\
1.17\end{array}$ & $\begin{array}{l}-- \\
-- \\
--\end{array}$ & $\begin{array}{l}-- \\
-- \\
--\end{array}$ \\
\hline
\end{tabular}

Acceleration

$\begin{array}{rrrrrrr}\text { IARL } & & & & -- & - & 11.00 \\ \text { LATL } & 395.3 & 12.97 & \sim 1.27 & -- & -- & 2.00 \\ \text { LAVL } & & & & - & -- & 1.65 \\ \text { LAR2 } & & & & -- & -- & 12.50 \\ \text { LAT2 } & 395.9 & 12.99 & \sim 1.27 & -- & -- & 1.35 \\ \text { LAV2 } & & & & -- & - & 1.70\end{array}$

\footnotetext{
*Indlcated stresses, using caltbrations discussed in Append Ix A.
} 
In a gimilar way, we can examine the peak stress data vo the range data on a log-log plot (Figure 4). Includiag another cycle on the ordinate would show that the 60-kbar data fall olightly sbove the fitted line. Stress values were obtained with currently available gage calibrations wich, however, may be erroneous because of a possible under-registration effect for the fiuid-coupled gages and becauge the one-dimension strain, or hydrostatic loading, experienced in calibration experimenta may not be appropriate to the triaxial loading in the field experiment. These effects are briefiy discursed in Appendix A. With all the data points shown in Figure 4, a least-squares power tit gives

$$
\sigma(\mathrm{kbar})=14.0 \mathrm{R}^{-1.88}
$$

where $R$ is the range in $r$. This peak-otress decay is very close to the Fit of $R^{-1.882}$ obtained by Bass ${ }^{1}$ for nuclear events in wer tuff in Rainier Mesa. The fit also compares favorab?y with data collected from previous (454-kg) 1000-1b idE detonations in wet tuff, which yield

$$
\sigma=15.6 \mathrm{R}^{-1.87}
$$

Thus peak stress date from this event are consistent with data from previous work in wet tuff.

\section{0-Kilobar Gageg}

Besides the work on residual stresa, this experiment provided an opportunity to test other gages. Four gages were located $9 \mathrm{~cm}$ from the

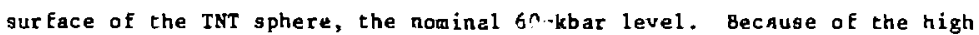
stresses and severe accelerationa, we did nat expect these gages to survive the peak stress and measure residual stress. 


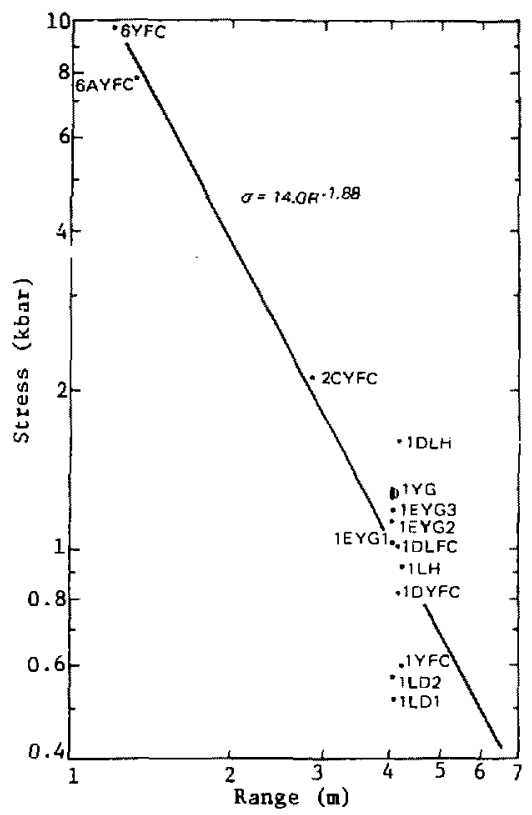

Figure 4. Measured Peak Stress vs Range

Gages 60CK and 60MK were the same type that had been used in the nuclear event HYBLA COLD. During that event, we had obtained credible waveforms except that polarities appeared to have been reversed.

Extensive investigation convinced us that it was a problem in the gage, and not a simple polarity charge. The probable cause was the epoxy around the grid beconing conductive under the 50- to 100-kbar shock loading. The output signal, then, was the result of the stress-induced resistance change in the piezoresistive grid being shunted by the stress-induced conductivity in the grid host. The resulting negetive trace showed that the nonductivity was the stronger of the two. PUFF TOO offered an opportunity to test this hypothesis and possibly to obtain a correction factor. 
The gage packages for HYBLA GOLD had congisted of a sensing grid epoxied between two hemi-cylinders of lucite and potted in an aluminum can. This package was $7.6-\mathrm{cm}(3 \mathrm{in})$ in diameter and $91.4 \mathrm{~cm}$ (36 in) in length and its axis was radial to the charge, thus loading the gensing grid end on. The disadvantage of this scheme is that there is a slight smearing of the rise time, about $7 \mu \mathrm{s}$, because of the time needed by the stress wave to cross the grid. A potential advantage is that survival should be significantly longer than that of the nomal grid configuration in which the grid is loaded perpendicularly to a radial line from the charge, or parallel to the wave front. Gage 60MK was the spare for the HYBLA GOLD and contained a 44-ohm manganin grid. Figure 5 shows its recorded output. After the arrival time of $85.5 \mu \mathrm{s}$, the trace goes negative, reaches a magnitude of $-0.3 \mathrm{~V}$ at $87.5 \mu \mathrm{s}$, then rises to the positive band edge. The latter rise is probably caused by gage breakage. Using calibration data, the $-0.3 \mathrm{~V}$ is equivalent to a decrease in gage resistance of 2.94 ohms. Gage $60 \mathrm{CK}$ was identical to $60 \mathrm{MK}$ except that the grid was a 95-ohm constantan element. Rosenberg ${ }^{2}$ has shown that, unlike manganin, constantan has a negligible piezoresistive coefficient, thus the gage should respond only to the conductivity effect. Following atresswave arrival at $80 \mu \mathrm{s}$, the constantan grid also shows negative signal with one peak of $-2 \mathrm{~V}$ at $83 \mu \mathrm{s}$, followed by a $-4 \mathrm{~V}$ spike at $87 \mu \mathrm{s}$. Again the rise to positive band is probably caused by breakage and occurs about $10 \mathrm{\mu s}$ after TOA. The two voltage levels represent resistance decreases of 19.1 ohms and $38.3 \mathrm{ohms}$ respectively. 

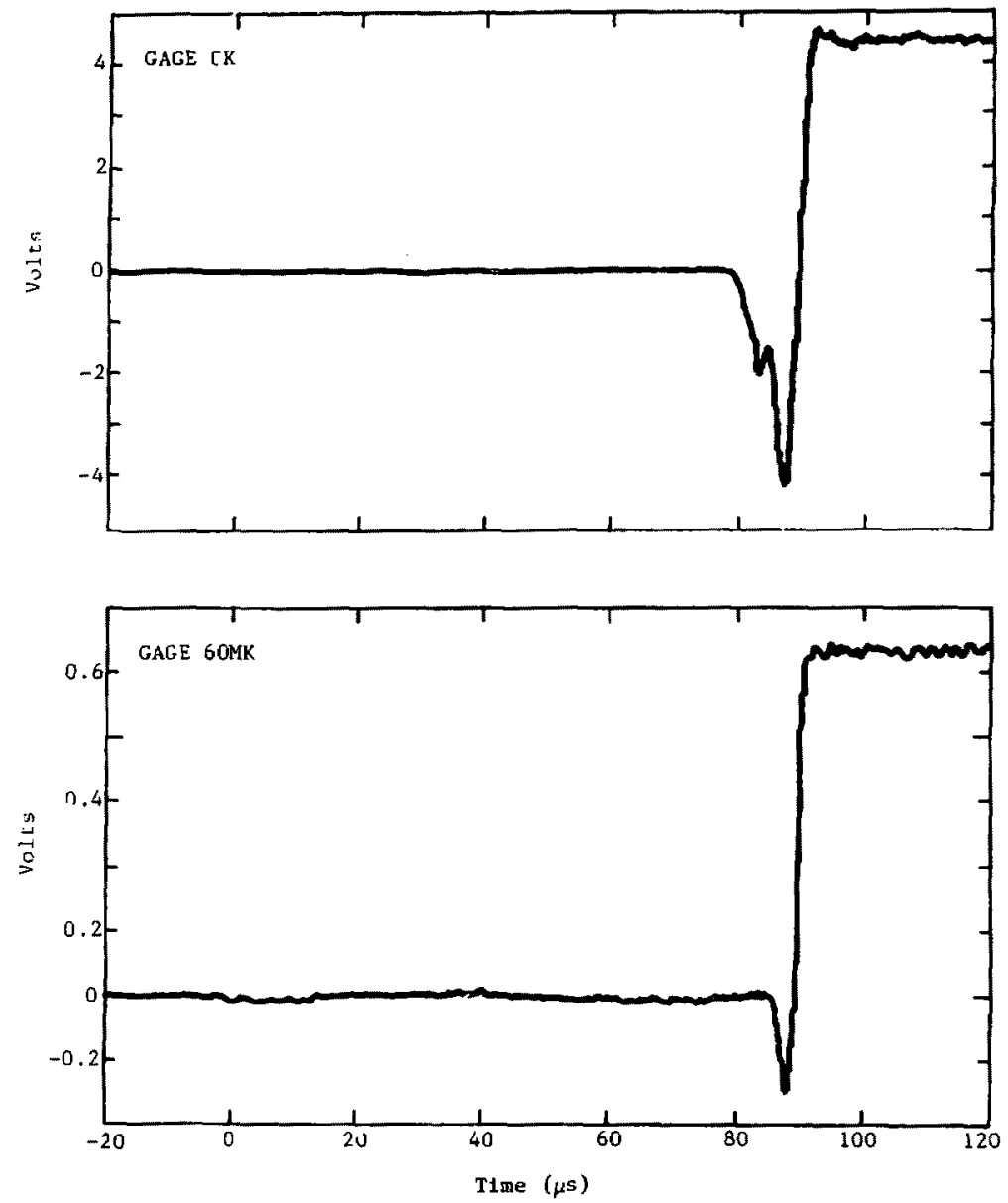

Figure 5. Constantan and Manganic Gages 60CK and 60MK 
In PUFF TOO the ge gages broke earlier than expected and we did not obtain a correction for the HYBLA GOLD gages. The polarity of the traces and the relative signal magnitudes are consistent vith the stress-induced conductivity bypotheais. We can, however, exanine the conatantan (CK) and manganin (MK) wave forms in detail and extract some bita of data. From the TOA to breakage, 60CR lastg $7 \mu 8$ and $60 \mathrm{MK} 2 \mu \mathrm{g}$ (Figure 5). Since we know the grid dimensions and the shock velocity in lucite, we can calculate that the transit time along the length $c F$ the grid is $7 \mu s$.

Therefore, it appears that the constantan broke wen the shock-uave front reached the leads at the end of the grid and the manganin broke when $2 / 7$ of the grid had been engulfed. About $2 \mu$ after TOA on 60CR, we see a negative 2-V signal. This resistance change is probably due solely to a conductivity, that is, a shunting effect in the host material. The shunt riecessary to generate the $-2 \mathrm{~V}$ is 377.5 ohms. This shunt may be added in an equivalent circuit for the manganin gage and a value extracted for the stresa-induced $\Delta R$ change in that portion of the manganin grid that had been engulfed at breakage. Wa obtain a gtress-induced resistance ( $\Delta R$ ) change of 2.07 ohws. Sine only $2 / 7$ of the grid had been pressured, the $\Delta R / R_{0}$ is

$$
\frac{2.07}{(2 / 7) 44}
$$

Uaing the usual calibration for manganin,

$$
\mathrm{P}(\mathrm{kbar})=350 \frac{\Delta R}{R_{0}}
$$

we obtain a pressure of $57.6 \mathrm{kbar}$. The other gages (6OMP and 60MR) at this location show this to be a reasonsble value.

If we revieu the HYBLA GOLD waveforma, we notice that the ohunting effect varies with input pressure and that the analysis--as perfotmed sbave-rielda data on only one point along the curve. One redeeting feature ia tiat assumed values of pressure for HYBLA GOLD give reagonable 
values of shunt resistance, suggesting the plausibility of the asoumed conductivicy mechanism.

In addition to the two sylindrical gages near the explosive, we fielded two traditional-style manganin gagea; these consist of short cylindrical slugs with the plane of the piezoresiotive grid parallel to the wave front. Gage 60MR consist of a 50-ohm $8 \mathrm{rid}$ embedded in a masscartable epoxy (REN RP-3269-1) with two RG213 coaxial cables leading vut the back. We used only the center conductor of the copw in order to enhance survival of the lead lines. Gage 60MP had a 50-olrm manganin grid embedde 1 in an epoxy cylinder and a sheet metal can around the cylinder. The can plus the shield of a single lead of RG215 couxial cable, acted as an electrastatic shiteld around the gage. Figure 6 shovs an initial pressure peak of $52 \mathrm{kbar}$, followe d by a rising trace. There is some detail at $122 \mu \mathrm{s}$ and electrical breakage at $128 \mu \mathrm{s}$. The waveform for gage 60MR shows pickup before the grress wave arrives, an initial peak stress of $63 \mathrm{kbar}$, a positive and negative spike starting at $126 \mathrm{\mu s}$, and an electrical short at $288 \mu \mathrm{s}$. The difference in peak-stress anplitude is probably caused by the difference in shock impedance of the tro epoxies. The rising trsce after the first peak on 60MP is probabiy associated with lateral otrain caused by the spherically diverging wave-manganin atts like a otrain gage when pulled laterally and exhibits a positive resistance strain coefficient From known shock velocities and thicknesses of

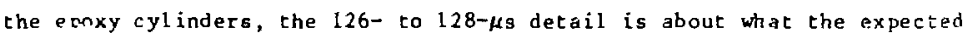
TOA or we stress wave would he at the back of the gages. The 6OMP opened electrically at this time and the 60Mr with its double coax, continued to record until the leads shorted out at $288 \mu \mathrm{s}$. At $288 \mu \mathrm{s}$, the wave front is $1.13 \mathrm{~m}(3.6 \mathrm{ft})$ from the charge center; we do not know why the leads shorted at this time. Usually, this gage configuration at the 50- to 60-kbar level produces arrival information and stress peaks but other phenomena affect pressure unloading. The electrical shield helped minimize electrical pickup. 

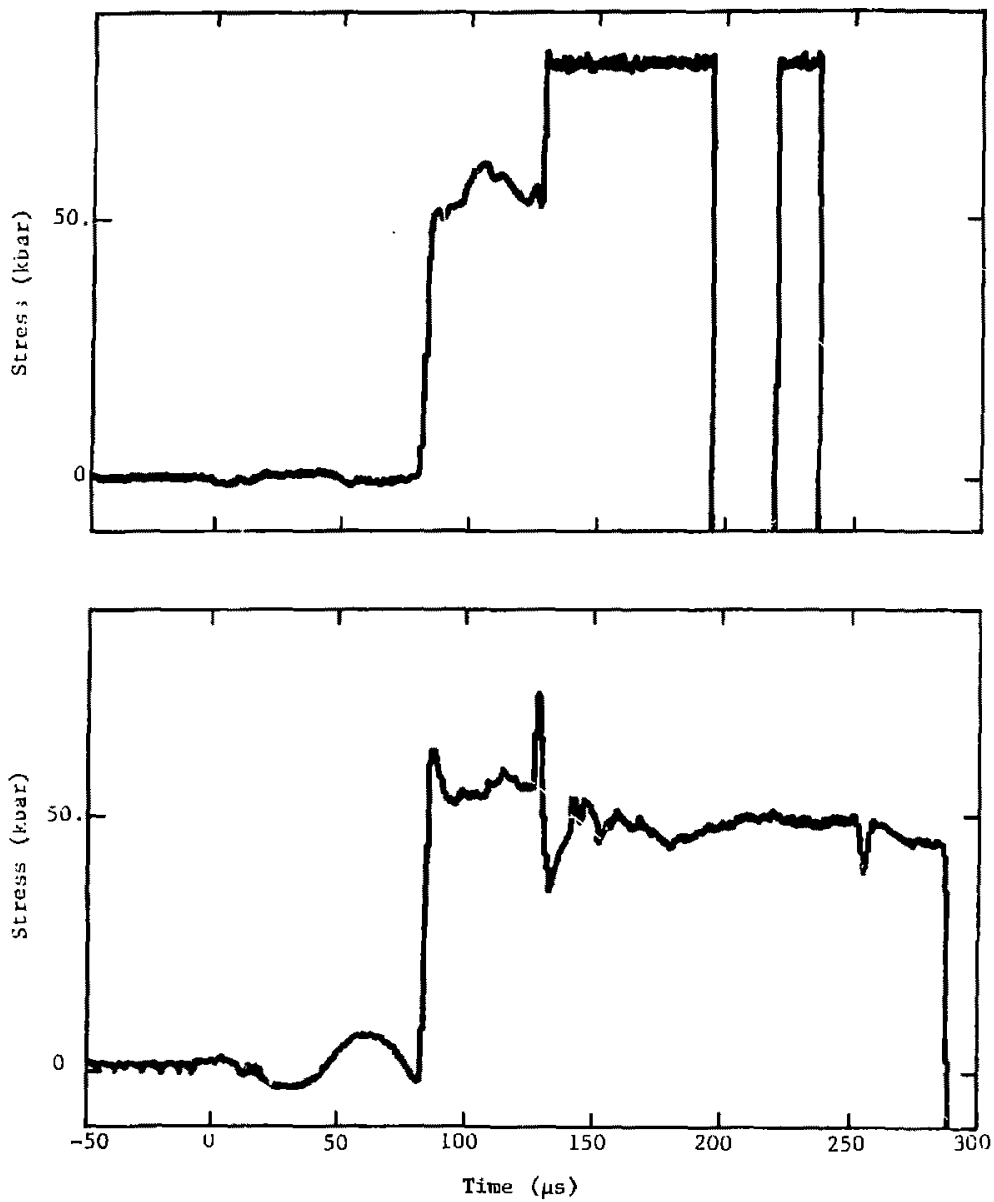

Figure 6. Manganin Gages 60MP and 60MR 
Close to the 60-kbar gages we placed a "dumy gage," that is, a noisestudy cable (6ONSI) to observe the interaction of the stress wave and a signal cable. This was an RG22 cable wose end was lacated 139.3 cro from the charge cencer. Ac the signal conditioner end of the cablo, wa attached a fixed capacitor. The cotal capacitance of the cable and a apaitor was $0.15 \mathrm{\mu F}$. This configuration was electrically similar to a ithiur nisbate gage. It was calibrated at $2 \mathrm{~V}$ and the band edges were set at \pm 2.2 and $\pm 10 \mathrm{~V}$. Figure? shows the output of 6ONSl.

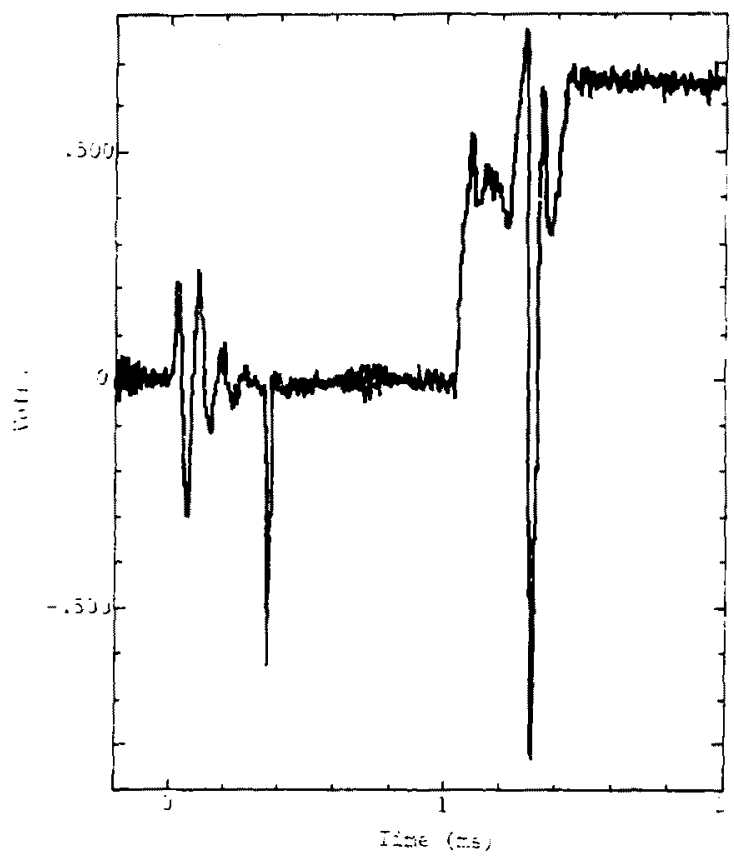

Figure ?. "Dummy Gage" Gonsl 
In the 0- to 200-ps portion of the record, we see oscillations that suggest "detonation" noise. At $350 \mu \mathrm{s}$, there uan a sharp negetive apike. The time of this spike coincide within $5 \mu \mathrm{s}$, with the azrival of the stress wave at Gage 6BLH which produced a negative 1S- $\nabla$ signal, indicating that the apike on 60NSl may have been crosatalk. We would expect the atresa vave to arrive at the end of the 60NS at $370 \mu \mathrm{g}$, yet we see no evidence of the arrival. Perhaps it was buried in the 6BLH pickup. At 1.02 ms we see a positive arrival. This TOA coincided with that of Gage 2CLH which produced a 10.8-V positive signal. After thie arrival the voltage oscillated about $0.5 \mathrm{~V}$, representing a charge on the cable of about 100 nanocoulombs $(\mathrm{nC})$.

This experiment showed that RG22 cable teminating in a capacitor can readily senae overvolcage signal a from other gages and shows an ourput which is probably gtress-induced.

\section{6-Kilobar Gages}

At the nominal 6-kbar level about 1.2 m from the charge center, we located five paddle gages. Our interegt at this stress level was threefold:

- To compare the stress and the TOA arrival in the grout backfill with those of the tuff

- To determine the ability of fluid-coupled gages to survive and to measure residual stress

- To examine the survivability of lithium niobate gages

After the event, we discovered that some channels of the signal conditioning unit contained inappropriace resiators, producing RC decay of the input voltage level. With a time constant of $1.7 \mathrm{~ms}$, a $50-\mu \mathrm{s}$ phenomenon will show negligible distortion while a 1 -ms phenomenon will produce sbout a 50\% error. Traces frow these channels were corrected.

Gage 6AYFC was a fluid-coupled ytterbium gage which we installed in tuff; its gignal conditioning unit contained an inappropriate resistor. Figure 8 shows the corrected woveform, with on observed peak of 
7.75 kbar. * Appendix C gives details of the correctiong, During corrections the time acale was shifted; zero time in the figure is when the atrese wave arrived at the gage $(0.348 \mathrm{mg})$. We believe the oocillation at the 4-to-5-kbar level is real gince we see it on other records fron gages in tuff. We see another mall oacillation near the l-kbar level. At gage breakage time, $2.3 \mathrm{~ms}$ after the time-of-arrival, the observed amplitude is 0.5 kbar.

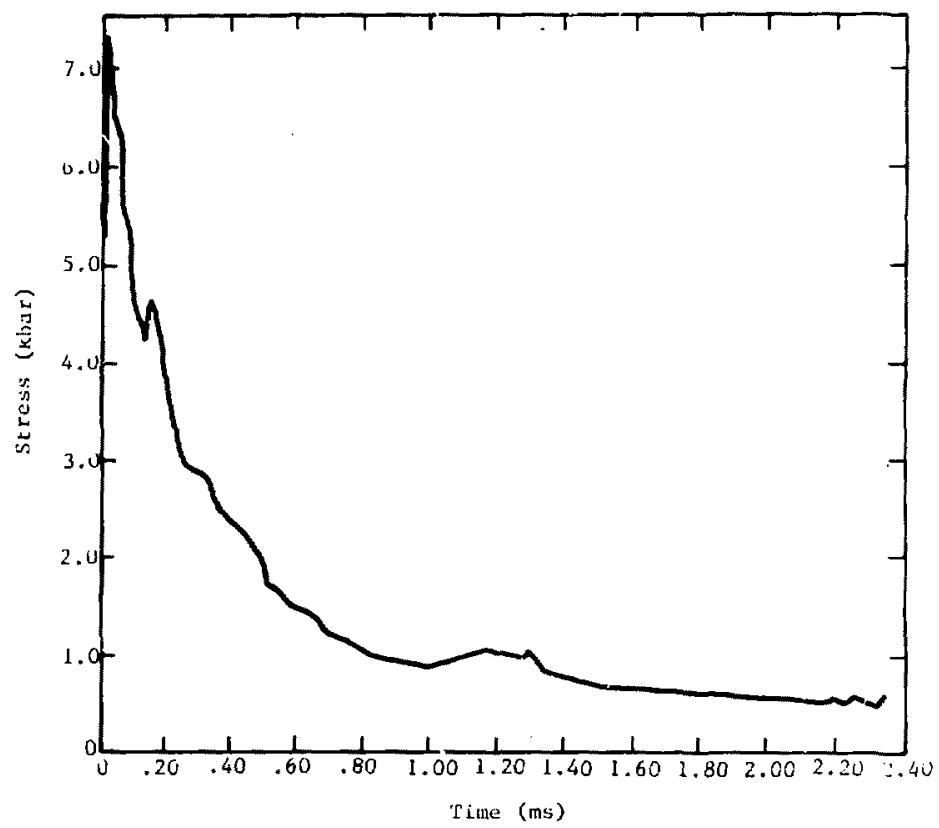

Figure 8. Corrected Fluid-Coupled Ytterbium Gage 6AYFC

"We have reduced the data for this and other fluid-coupled ytterbium gages by using the hydrostati: al ibration data (Appendix A). 
We placed Gage 6YFC, a fluid-coupled ytterbium paddle in the grout plug. Figure 9 shows the output. Following the rapid rise to $9.5 \mathrm{kbar}$, the wavefora decays and shows electrical breaka at 490 and $620 \mu 8$ of the lithium niobate paddles one (6LH) was imbedded in the grout backfill and two (6BLH and 6BLFC) were in drill holes. The two bolid-coupled paddles (6LH and 6BLH) produced spurious waveforms (Eigure 10). The negative voltage, starting about $1.1 \mathrm{~ms}$, is comon to both and appears to be crose talk. The fluid-coupled gage (6BLFC) ${ }^{\star}$ produced a more reasonable bhape (Figure 9) but the amplitude was too great for that range. The negative spikes at $0.348 \mathrm{~ms}$ and at $1.1 \mathrm{~ms}$ appear to be pickup from $5 \mathrm{BLH}$.

The ytterbium fluid-coupled gages at this nominal 6-kbar level produced reasonable wavefozms al though they did not ourvive long enough to measure residual stress; cable breskage is suspected. The lithium niobate gages did not surviva the 6- to 10 -kbar level, although the fluid coupling seemed to give a more raasonable shape. We believe that the solid coupled -rystals are fracturing; we have no plausible explanation for the enhanced output of the fluid coupled crystal.

\section{I-Ki lobar Gages}

At the norinal 2-kbar stress level, we grouted two stress gages in $A$ drill hole. Figure 11 show the output from oue gage, the fluid-coupled ytterbium paddle ( $2 C Y F C)$. The peak amplitude is band-edge limited, for the backup channel showg the peak to be 2,1 kbar (The backup channel has a poor signal-to-noise ratio which obscures unloading oscillations.) The wave form rises rapidly to a peak atress and it umloading portion contains oscillations similar to those obtained froo the 6AYFC. The trace then settlej to 0.22 kbar and shows electrical failure at $9.2 \mathrm{~ms}$.

\footnotetext{
*We have reduced the data from the fluid- and solid-coupled lithium niobate gages by using the lithium ninbate hydrogtatic coefficient (Append $i x$ A)
} 
The other gage (2CLH) in the drill hole was a colid-coupled lithitm niobace paddle. Figure 12 show a TOA of 1.03 ma, a olope change st 2.7-kbar amplitude, an oscillation, and then a rige to the 10-kbar band edge.
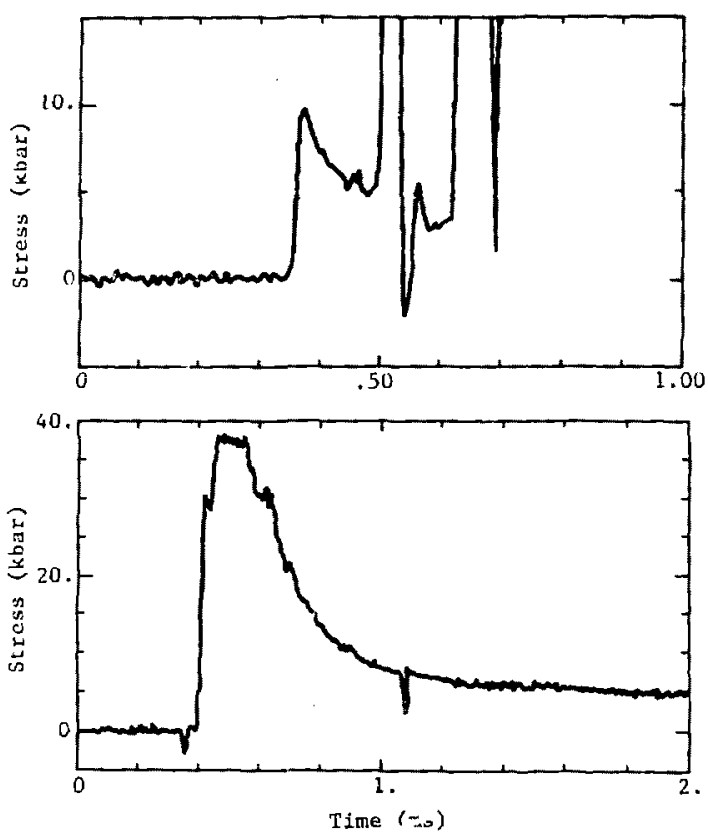

Figure 9. Fluid-Coupled Ytterbium Gage 6YFC and FluidCoupled Lithiun Niobate Gage 6BLFC 

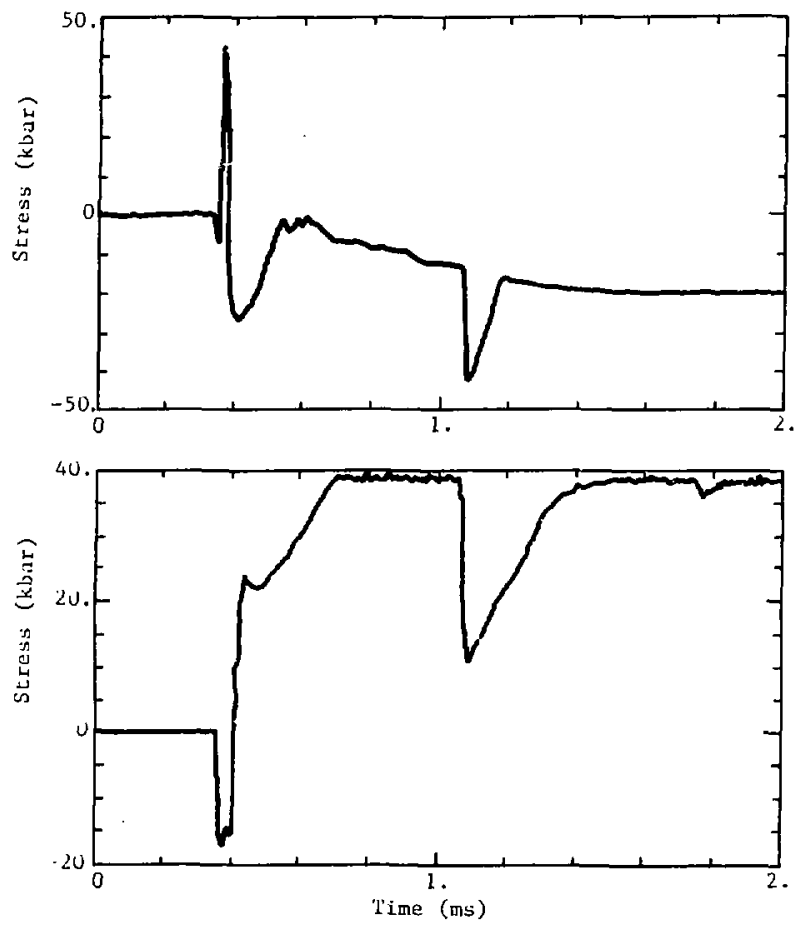

Figure 10. Solid-Coupled Lithium Niobate Gages 6LH and 6BLH 


$$
\text { K }
$$




\section{Time-of-Arrival Detectors}

We installed four stock TOA detectors at the nominal 2-kbar level in the grout steming plug. We were interested in the prolonged response generated by these detectors when used in the open circuit, long time constant mode to sense multiple wave errivals. Ususlly the short cirsuit, current mode is used with these detectors to eliminate all but the sharp initial stress-wave arrival. In experiments with a single-point source of energy, these detectors work well. However, current experinents involve multiple sources and require that successive TOAs be observed. How well the TOA detector could be adapted to this requirement had to be examined.

These TOA detectors consist of $25-m m(1-i n)$ and $75-$ mul (3-in) lead zirconite titanate (PZT) rings potted in epoxy. Two TOA detectors, one of each diameter, were installed such that the incident wave impinged on the detector parallel to the ring axis. Two others, also of both diameters, were laad side-on. Previous laboratory work had established the sensitivity and output polarity of these devices. Figure 13 shows the output from the smaller rings. The $2 \mathrm{~T} 1 \mathrm{~S}$ was loaded sideron and ahows positive output, as expected; similarly the 2T1B was loaded end-on and shows a negative signal, again as expected. These simultaneous arrivals, however, were followed by additional output.

Figure 14 shows the output from the larger rings. The $2 \mathrm{~T} 3 \mathrm{~S}$ was sideloaded and shows a large output whose polarity is opposite of that expected. The 2T3B shows the expected polarity as well as significant subsequent energy. Polarity reversal on the $2 T 35$ could be caused by lead reversal at an electrical connection. Details of signals that arrived after the initial arrival may have been caused by ring failure.

This work has shown that when used in point-source detonations, stock TOA detectors produce useful first-energy arrival data which is followed by additional output. This additional output will obscure subsequent energy arrivals if the detector is used in a multiple energy source experiment. For this reason, we conclude that the stock TOA detectors cannot be used for the reliable detection of closely spaced arrivals. 

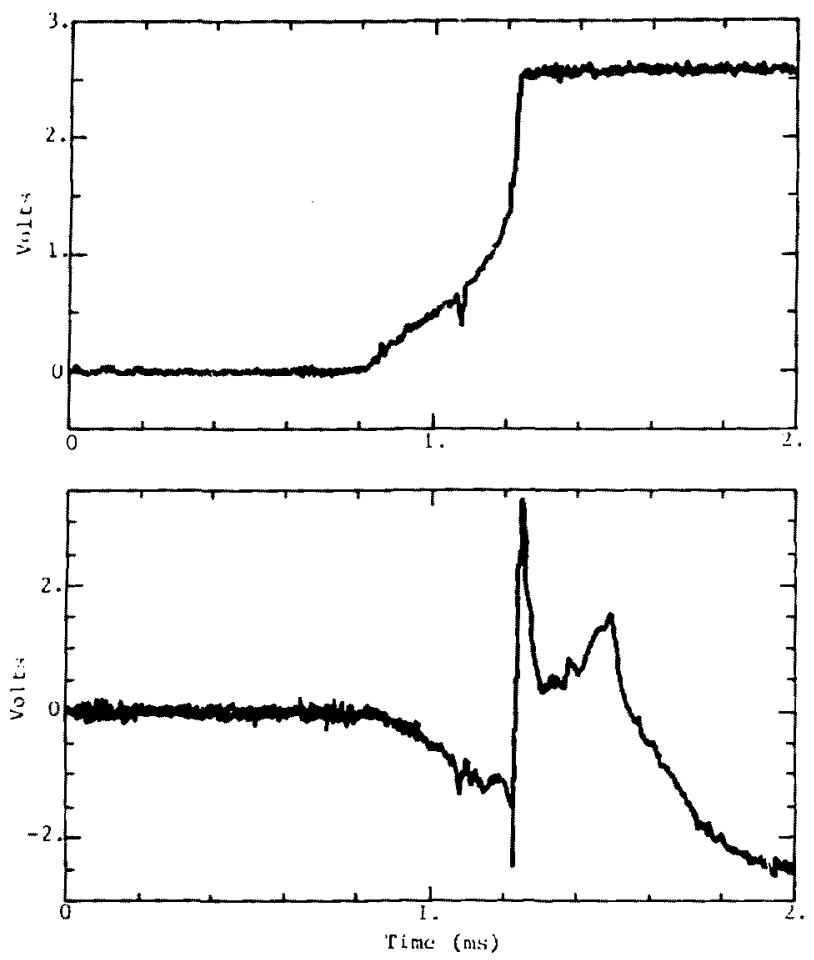

Figure 13. Time-of-Arrival Detectors $2 \mathrm{TlS}$ and 2TlB 

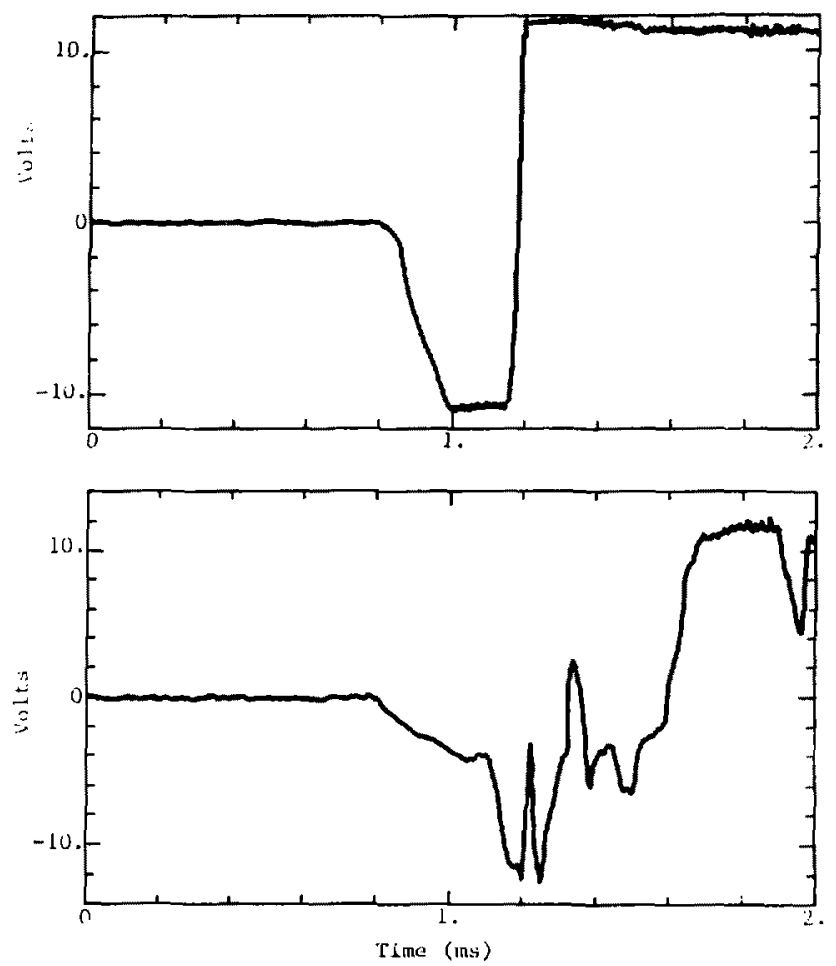

Figure 14. Time-of-Arrival Detectors $2 \mathrm{~T} 3 \mathrm{~S}$ and $2 \mathrm{~T} 3 \mathrm{~B}$

\section{Eluid-Coupled Plate Gage日}

Fluid-coupled plate (FCP) gages have been fielded on numerous nuclear events. A massive ateel version has been used to measure plasma flow in line-of-sight pipes with fagt rise times $(<100 \mu \mathrm{s})$ and peak pressures of up to l kbar. A smaller aluminum version has been used to make free-fiplt measurements ith rise-times longer than 1 ms and peak pressures up to 1 kbar. The gage consigts of a force plate in front of a fluid chamber in 
which transducers measure the pressure in the fluid. In PUFF TOO we installed three FPCs: one was a ateel version, two were aluminum. We suspected that massiveness of the steel gage ( $3 F C P$ ) wight affect its response to the dynamic effects in a 454-kg event; however, it might respond correctly to the residual stresa.

Figure 15 shows the wave shapes obtained from gages 3FCP, 2FCP, and IFCP. The 3FCP was located $184.2 \mathrm{~cm}$ from the charge center; other data show this to be the 5-kbar level. The aignal rose rapidly to $12 \mathrm{kbar}$, oscillated about $6 \mathrm{kbar}$, and then an electrical lead broke. Because of an impedance mismatch between the ateel case and the grout, we expected an oyershoor phenomenon. A finite element code calculation, HONDO, was performed to see if the observed response of this FCP gage in rock-matching grout was reasonable. With an input waveshape extrapolated from a closerin gage, the calculation showed that the output of the steel FCP should be a pulse with a peak of about $12 \mathrm{kbar}$ and a duration of about $100 \mu \mathrm{s}$. This is sinilar to the shape actually observed.

Gage $2 \mathrm{FCP}$, an aluminum unit, was turned $90^{\circ}$ in the stress field to measure residual hoop stress. Data show minor wave arrivals at 1.085 and $1.268 \mathrm{~ms}$ and a main arrival at $1.38 \mathrm{~ms}$. The earlier arrivals are consistent with arrival data from other gages and may represent a lowamplitude wave propagating through the housing to the sensing element well before the stress wave induced motion in the force place occurs. The trace rose to about $2.8 \mathrm{kbar}$ and indicated electrical failure about $300 \mu$ after the main arrival.

Data from lFCP, also an aluminum unit, show a main peak of about 0.5-ms duration and 0.8-kbar amplitude and a long-term offset of $0.2 \mathrm{kbar}$. Its duration is short compared to that of other gages at this location $(0.5 \mathrm{~ms}$ vs $2 \mathrm{~ms})$ but the long term offset is credible for residual stress. 

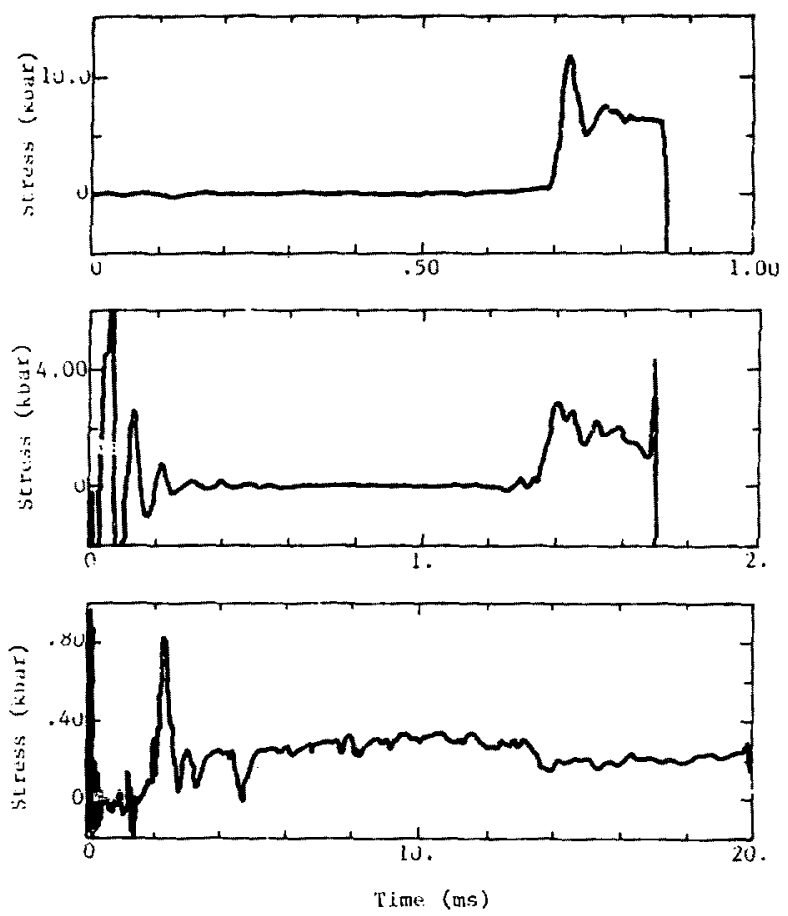

Figure 15. Fluid-Coupled Plate Gages 3FCP, 2FCP, and IFCP

The FCP gages respond to stress-wave input. With short rise times, we see strong overshont but for a rise time on the order of 0.5 mo we see none; however, the pulse length was shorter than that of served on other gages at this range. The data from the FCP gagea helped us understand gage responge better and measured residual stress at one location.

\section{Accelerometers}

One triaxial accelerometer package was placed in the grout stemming at the noninal l-kbar level. This so-called "rectangular" package 
contained three 50-kg piezoreaistive accelerometers (Endevco 2264A-50K-R) mounted on an aluinum base and covered by a thick aluminum cover. This configurarion was designed to prevent the atress wave from crushing the acceleroneters. The accelerometers were oriented orthogonally, IAR2 is the radial element (positive accelerstion is outward), lav2 is the vertical element (positive acceleration is up), and laT2 is the transverse element (positive acceleration is clockwise, looking down on the arrange ment). Figure 16 is data from 1 AR2, the radial accelerometer, and shows an arrival at $1.27 \mathrm{~ms}$, a rise-to-a-peak acceleration of $12.5 \mathrm{~kg}$, an abrupt drop to a negative $7 \mathrm{~kg}$, and a return to approximately zero acceleration at $2.5 \mathrm{mg}$. The record is clean and credible.

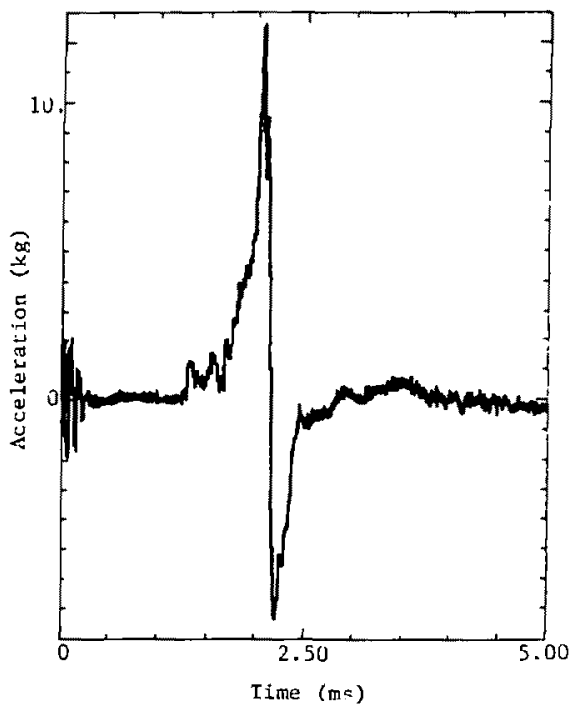

Figure 16. Radial Accelerometer IAR2

\footnotetext{
*hen used with acceleration, $\mathrm{kg}$ designates $1000 \mathrm{times} \mathrm{g}$, the acceleration due to gravity.
} 
Figure 17 ahows data irom the vertical (1AV2) and trangverse (IAT2) accelerometera. We processed the records normally, but they are quite noisy because the amplitudes were well below the $24-\mathrm{kg}$ band edge. The traces in Figure 17 have been filtered with a $25-\mathrm{kHz}$ low-pass digital filter; lAV2 shows o positive (up) peak of $1.7 \mathrm{~kg}$ and a shape similar to that of the radial gage, and lAT2 shows a positive acceleration of about $1.35 \mathrm{~kg}$. These traces suggest some asymmetry to the sphericity of the explosion. The gage package was placed in the grout plug about $40 \%$ of the way up from the floor and about $25 \%$ of the way across the plug.
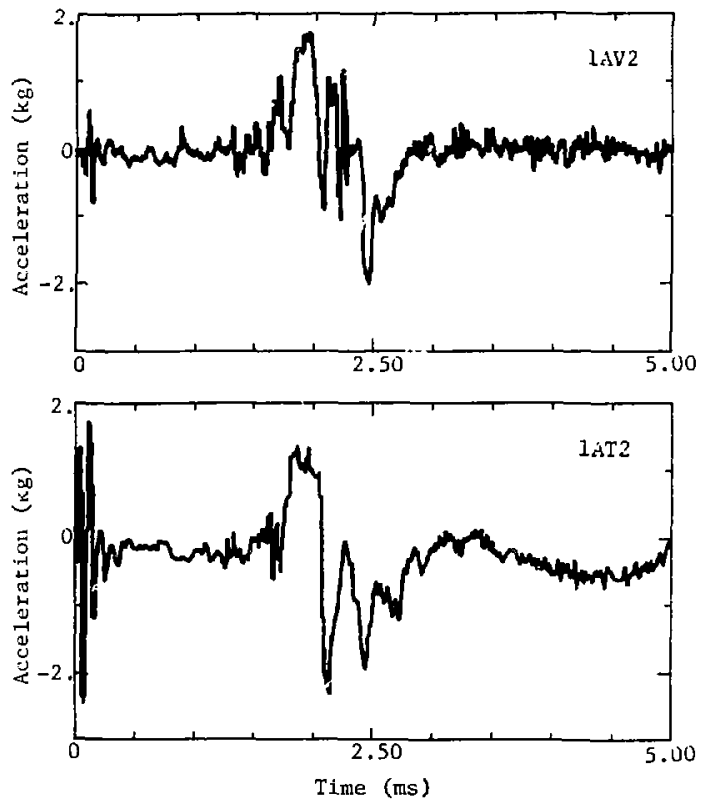

Figure 17. Vertical and Transverse Accelerometers lAV2 and IAT2 
Close to the rectangular gage we placed a triaxist bottle-shaped accelerometer package with the elements encapaulated in epoxy and so orientated that the radial accelerameter is aligned with the $8 x i s$ of the bottle. Data from this accelerometer, 1ARl (Figure 18), shows a shape sinilar to the radial accelerometer in the rectangular package. Between 1.9 and $2.0 \mathrm{~ms}$, there is a high-frequency high-amplitude "event." When we expand this interval, we find a damped sinusoid with a sharp onset. The ascillation periad is about $15 \mu \mathrm{g}(66 \mathrm{kHz})$, about twice the natural frequency of the accelerometer. This "event" is probably spurious gage response and not material acceleration. After a peak outwar' acceleration of $11 \mathrm{~kg}$, the trace drops rapidly to negative $6 \mathrm{~kg}$ and then returns to zero.

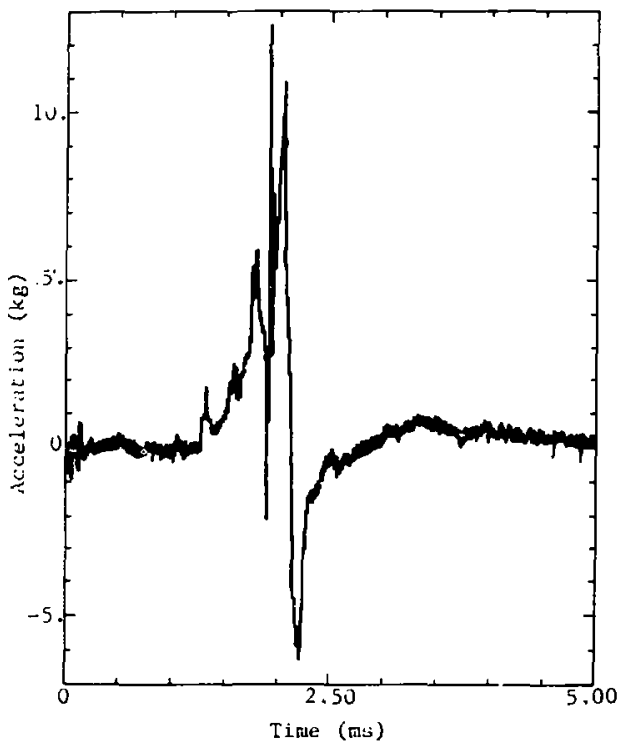

Figure 18. Radial Acceleroneter IARI

Figure 19 shows data from the other two components. The filtered vertical accelerometer ( $\mathrm{AV}$ ) shows a $1.65-\mathrm{kg}$ peak and a shape similar to 
that of the radial gage. The trangverae gage, lATl, show a aign conventinn that is the reverse of the other transverse component, laT2. We see a clockwise acceleration with a paak of $2 \mathrm{~kg}$ at $2,1 \mathrm{mg}$, at wich time there appeara to be large noibe pickup. Again, when we apread out the waveform, we see damped sinusold with duration that increases from $20 \mathrm{to}$ $40 \mu \mathrm{s}$ a $\mathrm{a}$ the amplitude lecays. The trace shows a negative 3-kg offoet indicating that the gage was damaged.
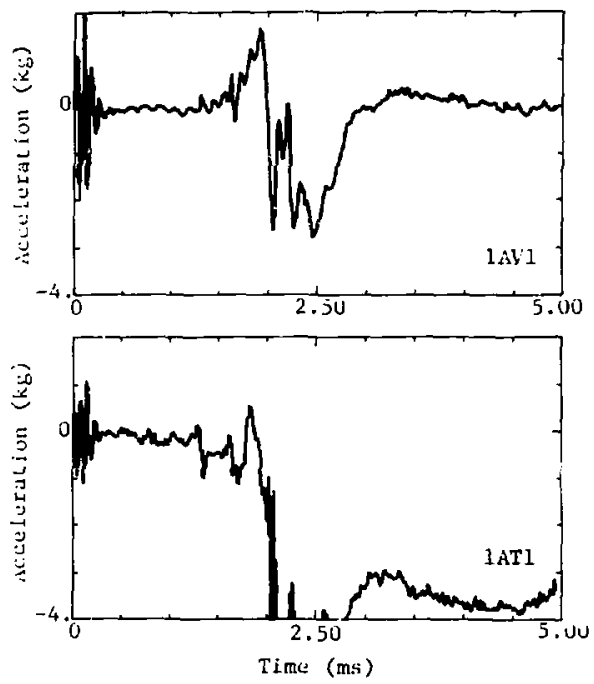

Eigure 19. Accelerometerg IAVI and IATL

The accelerometer packages, which we placed in the grout backfill $395 \mathrm{~cm}$ from the charge center show a peak radial acceleration of 11 to $12 \mathrm{~kg}$. Vertical and transverse components show peaks of up to $2 \mathrm{~kg}$. When we compare data from the epoxy bottle with those from aluminum rectangular packages, we see similar wave shapes and fewer noise spike from the rectangular package. 
To show the relationship between acceleration, particle velocity, and atress, ve have shown IAR2, the integral of $1 A R 2$ and ILH on a comon time base in Figure 20. It is often observed that acceleroweters usually show earlier TOAs than atreas gageo $(0.1 \mathrm{~ms}$ of difference $i$ due to the difference $i n$ distance. Here the first portion of the particle velocity waveform (integrated acceleration) is similar in shape to that of the stress waveform. This is to be expected: the stress wave induces particle motion and the theory of plane shock-wave propagation relates peak stress to peak particle velocity. The relation, $\sigma=\rho c u$, is not atrictly applicable here because we do not have a shock wave. Using the relation, however, the peak particle velocity of $(26.6 \mathrm{~m} / \mathrm{s}) 87.5 \mathrm{ft} / \mathrm{s}$ gives a very reasonable value of 1.1 hoar. In subsequent work, we vill examine at these records in more detail. For example, a power denaity apectrum will be studied to look for resonances that may affect the outpit.
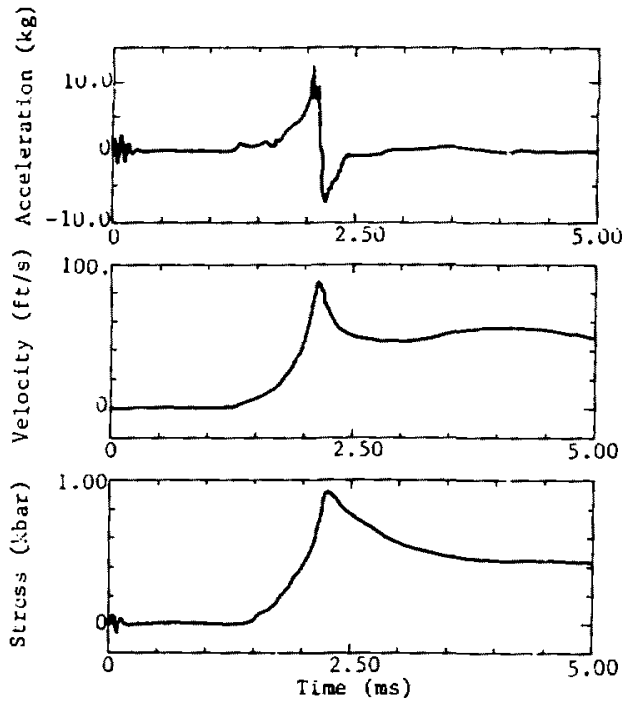

Figure 20. Accelerometer IAR2, Particle Velocity (from laR2), and Lithium Niobate Stress Gage lLH 
Iriaxial acceleroneter packagea aze sometimes uged in explosive events becauge their outputs and time integralo (velocity) provide useful diagnostica of wavefrant direction and particle velocity data. One problem with their use, however, has been in predicting aplitudes; computer calculations, with their artificial vigcosity, often give erroneous predictions. The PUFF roo event provided useful acceleration data for use in other work, and data to uge in comparing the two gage packages.

\section{1-Kilobar Gageg In Tuff}

At the nominal l-kbar range, we inserted gages into $10.2-\mathrm{cm}(4-\mathrm{in})-$ diameter holes drilled in the tuff and we coupled them to the tuff with a zock-matching grout (Figure 1). They were loaded "face on," the usual luading for paddle tyle gages. The D and E holes contained two lithium riobate gages, a ytterbium gage, and a ytterbium triaxial bottle gage.

Gage IDLFC (Figure 21) was a fluid-coupled lithium niobate paddle. After a rapid rise to a 1.02-kbar peak, we see one distinct dip in the unloading, at $4 \mathrm{ma}$, before the irace settles to a long-term residual stress of $0.26 \mathrm{kbar}$. Close to $1 \mathrm{DLFC}$, we placed a fluid-coupled ytterbium paddle, IDYFC, From this we see a waveform (Figure 22) similar in shape to that of the lithium niobate record, with a 0.83 -kbar peak, a dip at about 4 ms, and residual atress of $0.24 \mathrm{kbar}$. The trace has sone rapid detail on the peak. This is not a tape recorder band edge problem because the low sensitivity back-up channel shows the same amplitude. The oscillations beyond 20 ms show a period of about $15 \mathrm{mb}$ which, most likely, is ac pickup. Also show in Figure 22 is data from a aolid-coupled (PHA) Iithium niobate pad. dle gage, IDLH; the shape is similar to that of 1DLFC and IDYFC. The notable difference is in the peak amplitude $(1.6 \mathrm{kbar})$ and residual atress $(0.32 \mathrm{kbar})$. The differences in peak amplitudea probably reflect two effects: first, a potential underregiatration of fluid-coupled gages and second, we auspect the fluid-coupled gages are measuring mean stress and the oolid-coupled lithium niobate gage is meaning radial stress.

the fluid is more compressable than the gage package, thus a bridging, or underregiatration effect may occur. 
s.
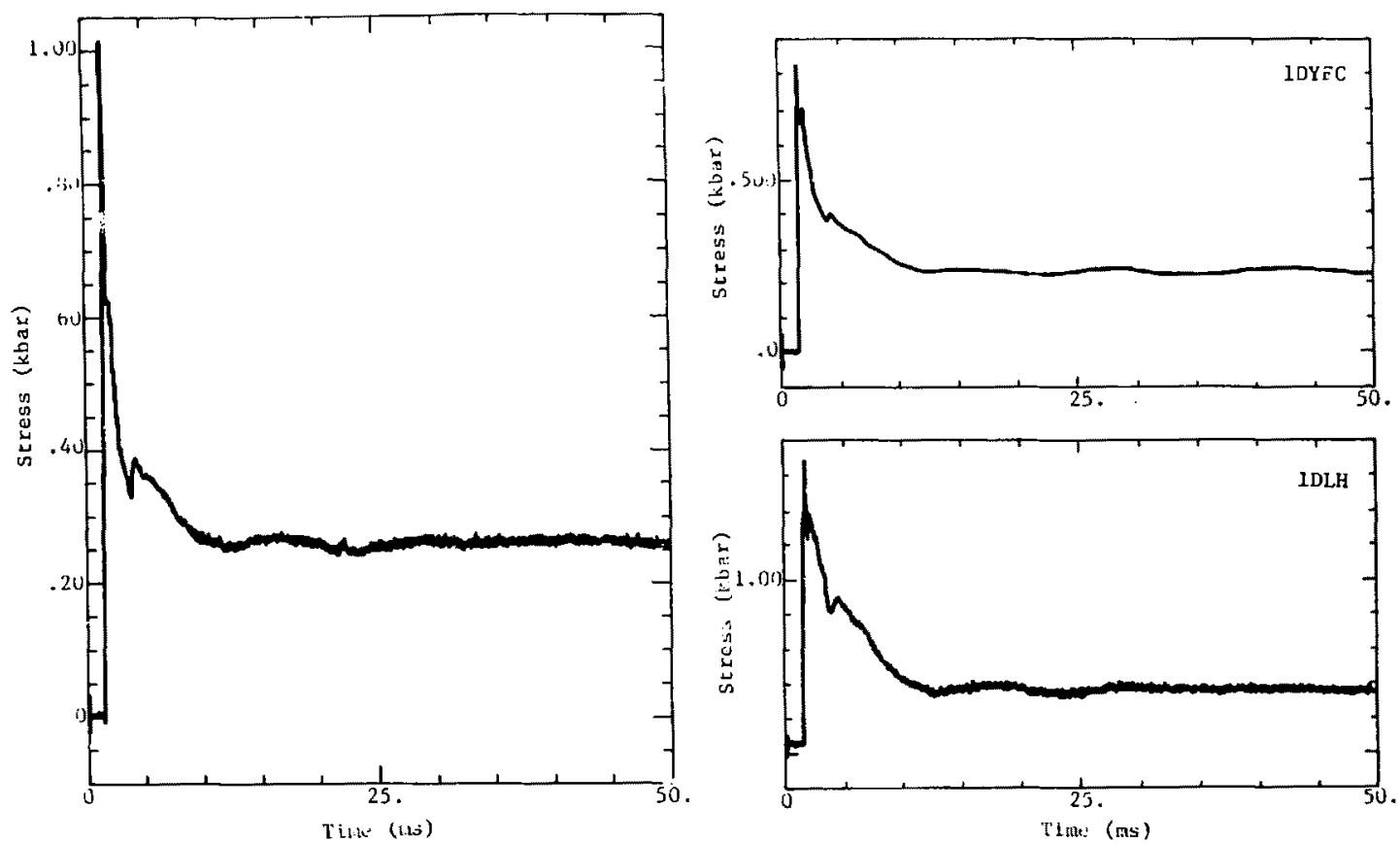

Figure 21. Fluid-Coupled Lithiun Niobate Gage IDLFC

Figure 22. Fluid-Coupled Ytrerbium Gage IDYFC and Solid-Coupled Lithium Niobate Gage IDLH 
The last gage in a drill hole was a triaxial ylterbium bottle with three senging eleqents: IEYGL, IEYG2, and IEYG3; Figure 23 shows the records. The peaks on G1, G2, and G3 are believable $(1.02,1.14$, and 1.17 kbar); ${ }^{*}$ on $1 E Y G 3$, the peak unloada similarly to the other gages in tuff and shows the start of a dip at $3.5 \mathrm{~ms}$. The trace then flattens out and subsequently shows two jumps that look like breaks in the electrical leadg. Elements G1 and G2 were recorded with signal canditioning channels that, through an error, had a too short an RC decay constant. These records were later corrected (see Appendix $C$ for discussion of the correction technique). Figures 24 and 25 show the corrected versions of elements G1 and G2. Note that this bottle gage was loaded aide on, thus the elements are orientated obliquely to a radial from the charge center. The residual amplitude on $G 1$ and $G 2$ contains two effects: reaidual stresa and gage hysceregia.

Ytterbium and lithium niobate gage records at the nominal l-kbar level show a shape which is characterized by a rapid riae to a peak stress, a gradual unlosding with a distinct dip at $4 \mathrm{~ms}$, and a sattling to a residual stress of about $0.27 \mathrm{kbar}$.

\section{l-kilobar Gages in Grout Stemuing}

We placed four atress gages in the grout stemning at the l-kbar nowinal amplitude. Two, IYFC and ILH, were paddle gages and the others were prototypes of a triaxial streas gage. The long-range application of the triaxial gages is to measure $\mu_{x}$ incipal stress components (Appendix A). They consist of three sensing elements on the orthogonal faceg of an epoxy cube which, in turn, is encapalated in an approximately cylindrical epoxy bottle. We aligned the axis of the bottle along a radial from the charge center.

* The one-dimengion atrain coefficient has been used to reduce the nonfluid-coupled ytterbium Bages (Appendix A). 

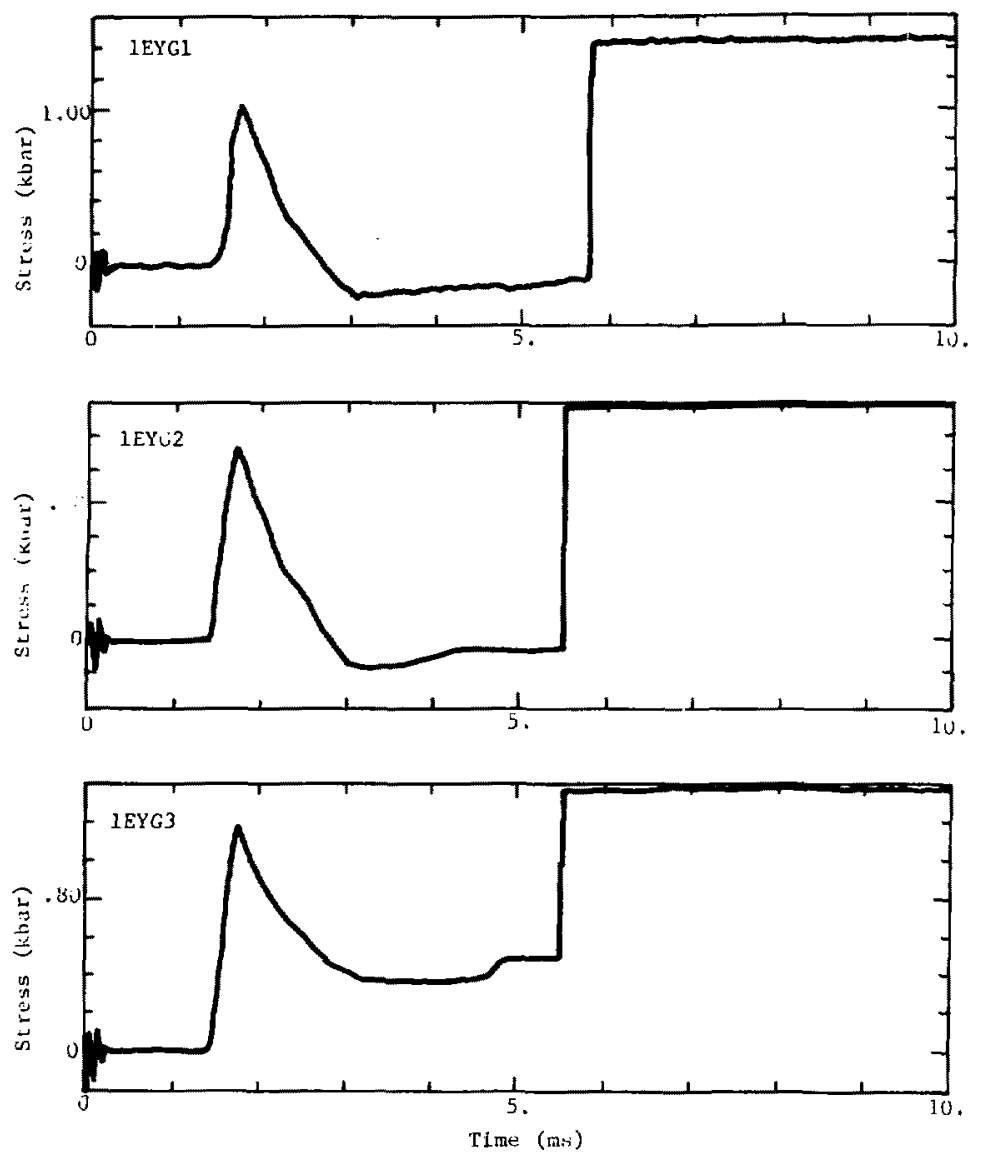

Figure 23. Triaxial Ytterbium Gage With Elements IEYGI, IEYG2, and IEYG3 


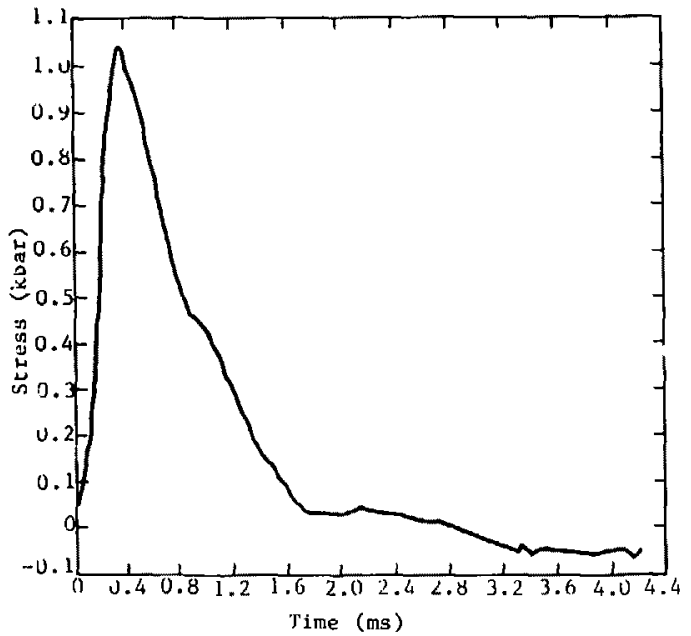

Figure 24. Corrected Version of IEYGl lage Element With Time leasured From TOA

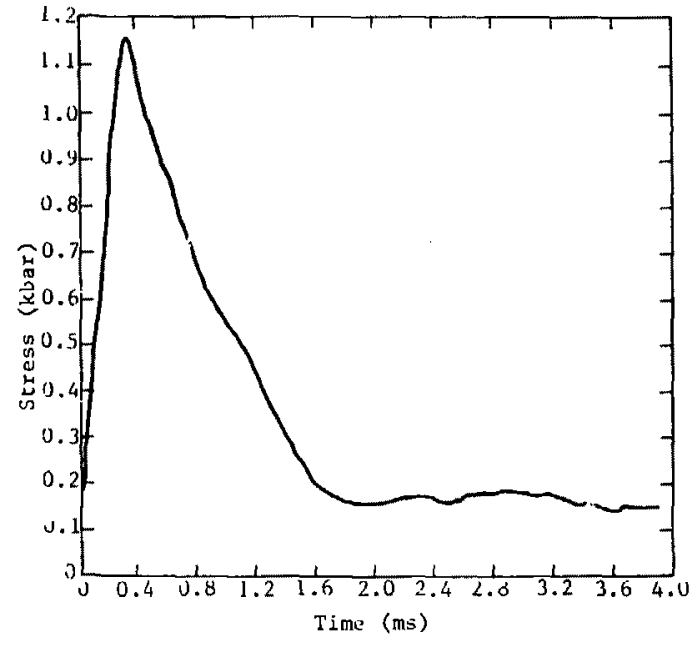

Figure 25. Corrected Version of IEYG2 Gage Element With Time Measured iron TOA 
The orthogonal faces in the gage are orientated such that the plane of each sensing element is about $35^{\circ}$ from the axia of the gage; the elements are symetrically apaced with respect to the boundaries of the epoxy hast. With the radial orientation of the gage package, we expected similar signals from each sensor - if the explosion produced an axially symatric struss field. The accelerometers (see above) showed that there was, in fact, some asymmetry of the stress field.

The ytterbium fluid-coupled gage lYFC (Figure 26) produced a rapid rise to a 0.6-kbar peak, the unloading showed oscillations at the 0.2- to 0.3 -kbar level, and setcled to $0.2 \mathrm{kbar}$ at $22 \mathrm{~ms}$. The waveform is quite bei ievable and indicates a late residual stress of 0.2 kbar.

The companian lithium niabate gage (1LF) was a solid-coupled paddle (PHA). Figura 26 shows a rapid rise to a $0.93-k b a r$ peak, some oscillation in the unloading, and finally a settling to 0.23 kbars at $22 \mathrm{~ms}$. Again, it appears we measured residual atress. Except for the minor difference between 3 to $8 \mathrm{mB}$, IYFC and $1 \mathrm{LH}$ are in remarkable agreement on wave form shape. The correct gage calibrations are unknawn; however, is we asoume that $1 \mathrm{LH}$ is correct, then the difference between 1LH and 1rFC suggests chat the fluid-coupled package causeg an under-registration effect of approximately $60 \%$ (Appendix A). * This is about the difference noted for the 1DLH and IDYFC in tufE. The data from the solid-coupled 1 ithium riobate triaxial gage with senging elements 1LD1, 1LD2, and 1Lu3 is shown i. Figure 27. Element lLDl ghows a peak of $0.52 \mathrm{kbar}$ and an oscillation in its unloading before it settles to a $0.185-k b a r$ offset. Elenent ILD2 differs from $1 \mathrm{LDl}$ in some of the unloading oscillations; its peak is $0.57 \mathrm{kbar}$ and itg long term amplitude is $0.15 \mathrm{kbar}$. The difference in the unloading oscillations of ILDl and ILD2 may be due to some arymetry of the gtreas field; 1LD3 was not recorded becauge of a field hookup error. These records are credible and tbe shapes are jimilar to paddle gages lLH and IYFC.

\footnotetext{
"Subsequent work suggests that solid-coupled lithium niobate gagea respond principally co the stress (which loads the face of the element). Thi inplies that lLH regponded to the dynamic radial streas. Gage IYFC is most likely trying to respond to the thean atreas.
} 

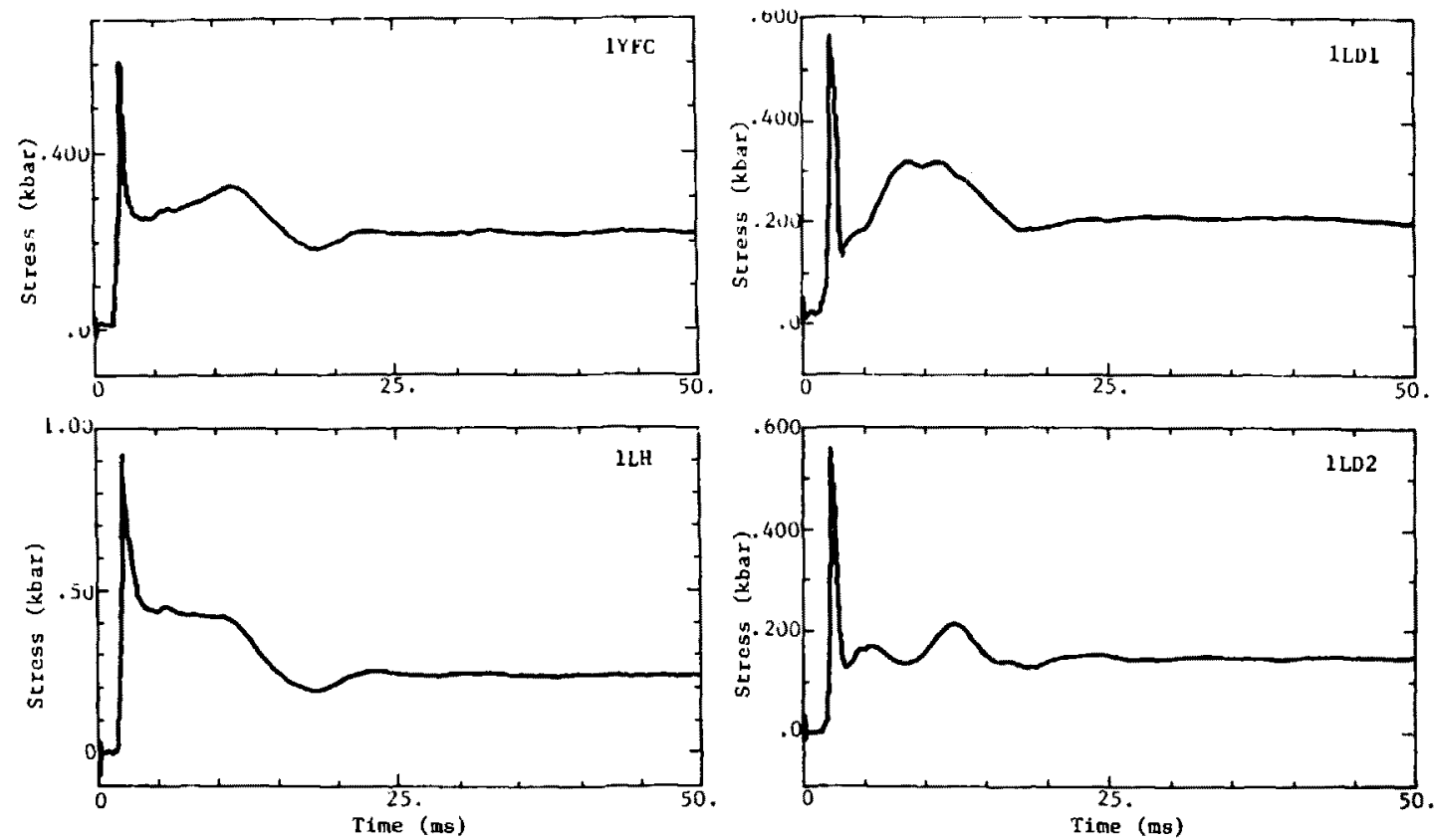

Figure 26. Fluid-Coupled Ytcerblum Gage 1YFC and Solid-Coupled Lithium Niobate Gage ILH

Figure 27. Lithium Niobate Triaxial Gage With Elements 1LD1 and 1LD2 
The aecond bottle gage at the l-kbar level containad three ytterbium grids. Figure 28 shows the traces produced by elements 1YG1, 1YG2, and 1YG3. Gage element Gl buffered from the incorrect resistor described previously. Figure 29 shows the corrected veraion.
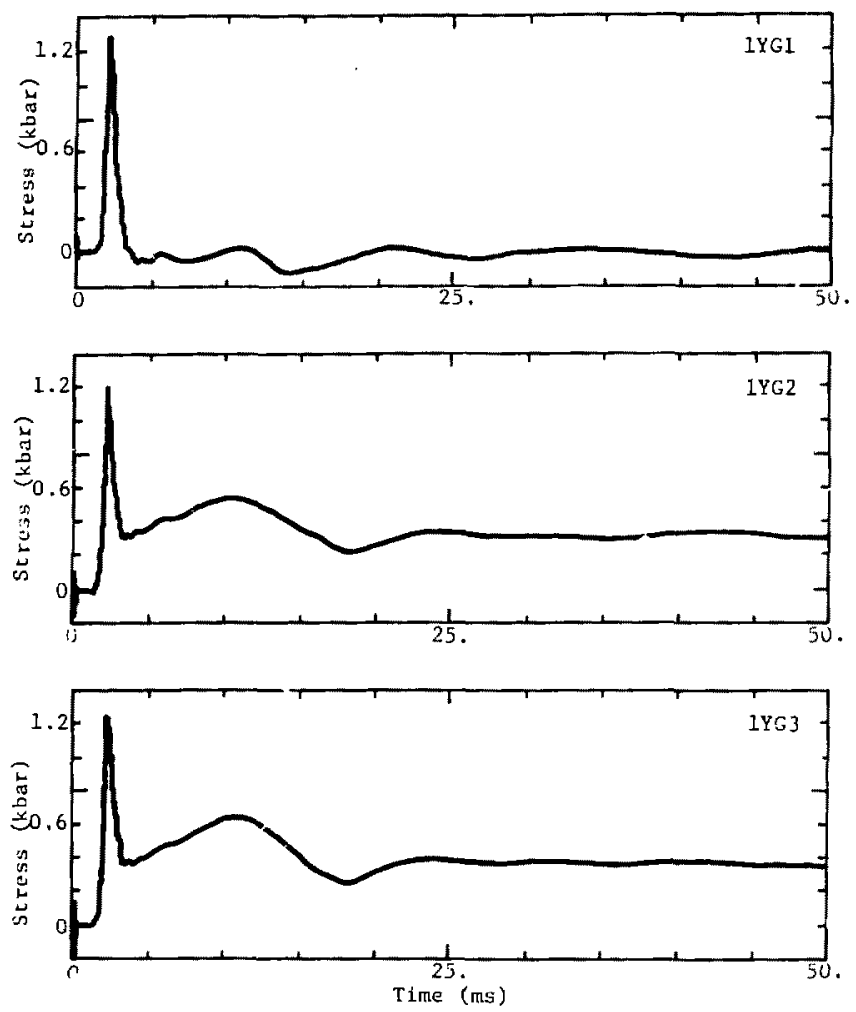

Figure 28. Triaxial Ytterbium Gage with Elements $1 Y G 1,1 Y G 2$, and $1 Y G 3$ 


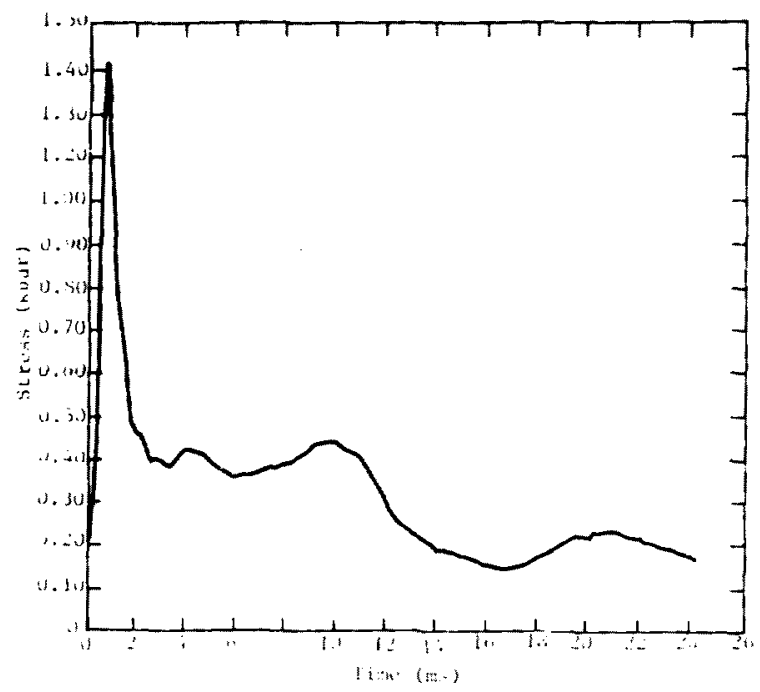

Eigure 29. Corrected Vergion of Element IYGI with Time Measured From TOA

Elements IYG 2 and IYG 3 produced similarly shaped waveforms, showing some oscillation in the unloading before settling to constant offset. If we use the one-dimensional strain coefficient, we see that the measured peatis and late time of

\begin{tabular}{ccccc} 
& & \multicolumn{2}{c}{ Offset } \\
\cline { 5 - 6 } IYGI & 1.24 & & - & - \\
IYG2 & 1.24 & & 0.3 & 0.0105 \\
1YGJ & 1.29 & & 0.36 & 0.0127
\end{tabular}

The peaks are believable; the late offsets contain the gum of the residual stress and the so-called hyteresis effect observed in ytterbium when it is not hydrostatically loaded.

If we carefully review Gingberg' a calibration work on ytrerbium, ${ }^{3}$ we find that, below 1 kbar, yterbium, loaded in uniaxial strain, shows no 
hysteresis; above 1 kbar, it showa increasing hysteresis. Ginaberg's calibration shot that is appropriate to IYG2 and $1 Y G 3$ is 57 , showing a peak stress of $1.27 \mathrm{kbar}$ and a zero stress offeet $\left(\Delta R / R_{0}\right)$ of 0.0052 . Confidence in this calibration shot is enhanced by the presence of two gage elements which show peak $\Delta R / R_{0}$ and residual values agreeing to within a fow percent. Subtracting the hybteresis effect from 1 YG2 and $1 Y G 3$ and cunverting to stress, we obtain residual atresses of 0.23 and $0.16 \mathrm{kbar}$.

The solid-coupled lithium niobate crystals and the fluid-coupled ytterbium elements in the grout steming show surprisingly similar waveshapes. Peak amplitudes vary by a factor of about two; we must, however, examine the element, its host, orientation, and, in general, the gages' response to the triaxial state of stress. The rise in stress after the 3.3-ms dip may be associated with the rebound of the far field material. Late residual stress tends to cluster about $0.19 \mathrm{kbar}$ and, in spite of differences in peak stresB, they agree well.* Also, the 0.19-kbar value closely agrees with the calculational results described in Appendix $B$.

Comparing the l-kbar gages in grout with those in tuff, we see that, typically, the gages in grout show a major oscillation between 3 to $20 \mathrm{~ms}$ which is not seen on the tuff gages. This difference in unloading behavior is probably due to a difference in the elastic-plastic hehavior between the tuff and the grout. Also, gages in tuff show an average residual stress of $0.25 \mathrm{kbar}$ and those in grout, $0.19 \mathrm{kbar}$.

\section{Cavity Pressure Measurements}

We attempted two cavity pressure measurements in the PUFF TOO experiment. Such measurements are of interest because it is the pressure that the residual stress field must withatand in order to contain the event. Also, cavity pressure and the rinal size of the cavity may be compared with computer calculations; agreement indicates that the explosion phenomenon has been modeled correctly.

\footnotetext{
*one can argue that in the late titue regine the gages are all measuring mean stress.
} 
To measure cavity pressure, we used a "blowdown" technique previously used on smaller charges. The equipment consisted of a quarter-litre volume pressure chamber, high-presaure tubing, ${ }^{\star}$ and an explosive valve. The pressure chamber, containing a preasure transducer, was located outside the grout stemming, and charged, before the shot, with nitrogen to about $69 \mathrm{MPa}\left(10000 \mathrm{lb} / \mathrm{in}^{2}\right)$. The tubing extended from the chamber through the grout oteming $p l u g$ and ended cloge enough to the high explosive so that the pipe tip was at the edge of or just inaide the final cavity. An explosive valve was located 3 to 7 m from the tip of the pipe. We fired the explosive valve $10 \mathrm{~ms}$ before the main charge, starting the flow of gas. As the cavity grows and engulfs the tip of the pipe, the pressure in the chamber "blows down" into the cavicy.

Data from our previous experience with this cechnique are shown in Figures 30 and 31 . The former shows measurements on three $3.63-\mathrm{kg}(8-1 \mathrm{~b})$ events, the latter on a $29-\mathrm{kg}(64-1 \mathrm{~b})$ event.

The time record is characterized by a rapid drop of pressure that terminates in an abrupt change of slope, which, in turn, is followed by a slow decay of pressure. Calculations involving turbulent flow through a long thin tub, Juplicate the rapid decay and slope change and show that the pressure at the slope change is the cavity preseure. The slow decay is due to cavity cooling and porous flow out of the cavity.

In PUFF TOO, we installed the CPI gage like we did the gages used on the smaller events; the tip of the tubing was 525 m (21 in) from the surface of the explosive and the tubing extended radially outward. On the $\mathrm{CP}$ gage we usec a variation of the same technique--a capped piece of tubing tangential to the explosive sphere. Circumferential grooves had been cut in the tube and the dynamic effects from the explosion were expected to break the pipe and allow the gas to flow, thus no explosive valve is used.

*The 4130 steel tubing has a 3.43-mm (0.135-in) ID, a 9.52-mm $(0.375-i n) O D$, and is rated at 6.7 -kbar tensile strength and $4.4-\mathrm{kbar}$ yield stress. 


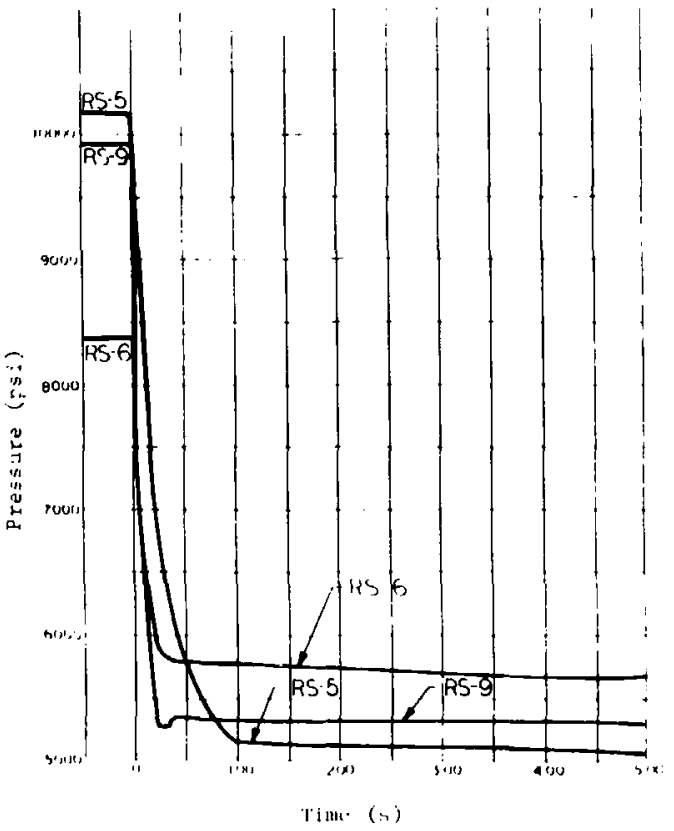

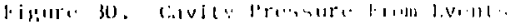
is; $3, k+1), .111$, $2:$,

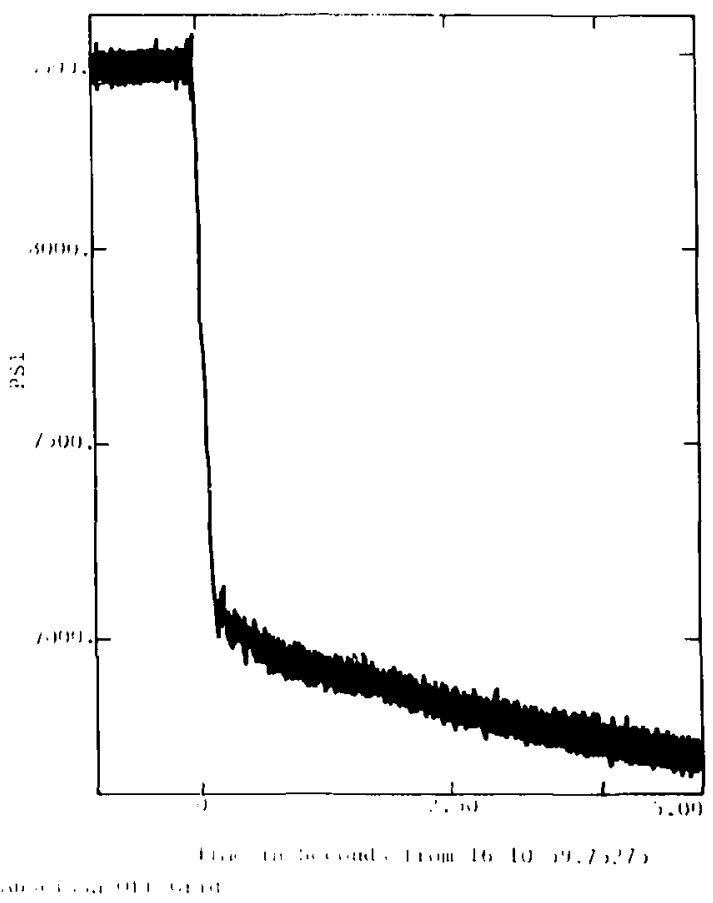

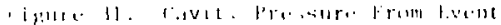
$\therefore-6 \quad(6,4)$, 
Figures 32 and 33 ghow the pressure time records obtained. The CPI (radial) chamber bleeds from $62.1 \mathrm{MPa}\left(9000 \mathrm{lb} / \mathrm{in}^{2}\right.$ ) initial pressure down to 5 :.0 MPa $\left(7400 \mathrm{Lb} / \mathrm{in}^{2}\right)$ and shows some osciliations. The fo-s record (Figure 33) shows a slight rise in pressure and then a low decay. The tangential gage starts at $72.4 \mathrm{KPa}\left(10500 \mathrm{lb} / \mathrm{in}^{2}\right)$ and decays to about $21.4 \mathrm{MPa}\left(3100 \mathrm{lb} / \mathrm{in}^{2}\right)$ at which point we see an inflection. The long term trace shows a slight rise, a slow decay, and a $2.1 \mathrm{MPa}\left(300 \mathrm{lb} / \mathrm{in}^{2}\right)$ jump at $48 \mathrm{~s}$.
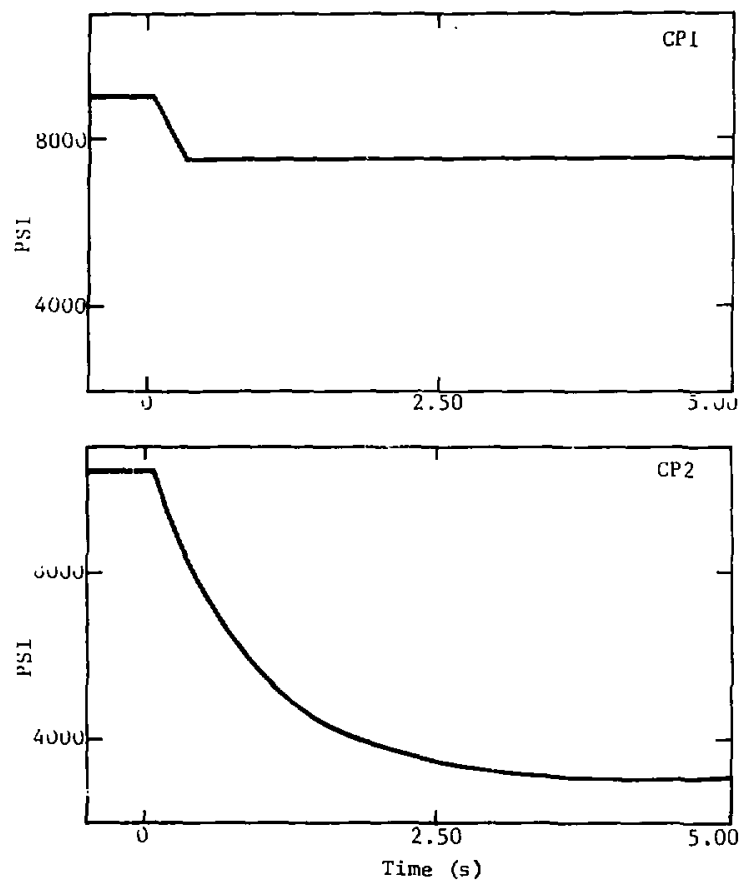

Figure 32. Cavity Pressure CPI and CP2 from Eveat RS-3 (0 to 5 s) 

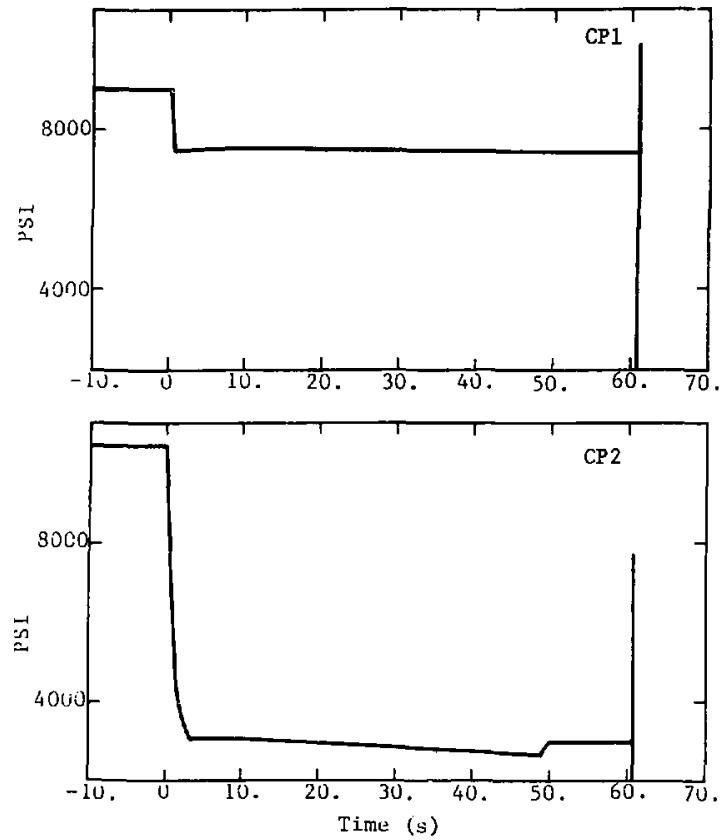

Figure 33. Cavity Pressure from RS-3 Event (0 to $70 \mathrm{~s}$ )

Mineback showed $15.2 \mathrm{~cm}(0.5 \mathrm{ft})$ of the CP1 pipe inside the cavity. This pipe, originally radial, had been bent to one side and the tip was jammed closed. In the grout, $183 \mathrm{~cm}(6 \mathrm{ft})$ from the charge center, there was a 4-mn gap in the pipe. The CP2 line was broken at the cavity wal1; the break appears to have been at one of the circumferential grooves. At $310.9 \mathrm{ctn}(10.2 \mathrm{ft})$ from the charge center was a kink in this pipe with a small axial split.

If the tip of CPI was jammed closed before pressure equilibrium was achieved, it signifies that the chanter pressure was higher than thet in the cavity. The 29-kg (54-1b) event also had a jamed tube and a cavity 
pressure of $49 \mathrm{MPa}\left(7100 \mathrm{1b} / \mathrm{in}^{2}\right)$. On the other hand, the CPI pressure record is similar in shape to the records from the $3.6-\mathrm{kg}$ (8-1b) events which are credible becauee mineback showed open pipes.

We encounter two problems when trying to interpret CP2 data. First, we have no previous experience with this tangential pipe arrangenent. Second is the split at $310.9 \mathrm{~cd}$. Two interpretations are possible. On the basis of past experience, CPI is credible and the cavity pressure was $51.0 \mathrm{MPa}$ ( $7400 \mathrm{psi})$. One, however, would like to be able to offer an explanation for the aignificantly lower cavity pressure measured by CP 2 . The alternate interpretation has CP2 measuring the cavity presaure and CPI bent and jammed closed during cavity growth and thus the chamber pressure was not in equilibricm with the cavity. The cavity pressure is probably bracketed by these two values. In future work we will examine the operation of the blowdown technique.

Postevent

Fracture Pressure Experiment

Four steel pipes, identical to thase we uaed to measure cavity pressure, were grouted in tuff near the charge center. After the event we had planned to pressurize these pipes with nitrogen to measure the pressure required to break out of the small cavity around the end of the pipes. Breakdown pressures should be related to the existence and atrength of the residual stress field. After the nitrogen had fractured the material, we planned to pump dyed water into the fractures so that mineback would reveal their direction. This is of interest becauge orientation of the fractures should reflect the strengtho of the hoop in relation to the radial residual stress fieid; fractures tend to open perpendicularly to the minimum component of the residual stress.

At $2.5 \mathrm{hr}$ after detonation, and before pressurizing them with nitrogen we checked the contents of these fracture pipes (FP) by opening the vslues at the bulkhead. FPI and FP2 showed no pressure or carbon monoxide 
(CO). FP3 "spitted" clean, followed by gray water, but contained no Co. FP4 showed a small volume of an explosive gas mixture, with 20000 PPM of Co, i,e. cavity gas, under about $0.350 \mathrm{MPa}\left(50 \mathrm{lb} / \mathrm{in}^{2}\right)$ pressure.

We pressurized FP4 with nitrogen at a moderate pumping rate. The pressure rose to $14.1 \mathrm{MPa}\left(2040 \mathrm{lb} / \mathrm{in}^{2}\right)$ at which point it dropped rapidly. Subseq.ant steady pumping showed a pressure of $9.66 \mathrm{MPa}\left(1400 \mathrm{lb} / \mathrm{in}^{2}\right)$. FP3 was similarly pressurized; showed a peak of $19.3 \mathrm{MPs}\left(28001 \mathrm{~b} / \mathrm{in}^{2}\right)$. FP2 and FP1 were pumped at a slower rate: FP2 showed a break at $15.0 \mathrm{MPa}$ (2180 $\left.\mathrm{lb} / \mathrm{in}^{2}\right)$ and settled to $12.4 \mathrm{MPa}\left(1800 \mathrm{lb} / \mathrm{in}^{2}\right)$; FPl broke at $30.3 \mathrm{MPa}$ $\left(4390 \mathrm{lb} / \mathrm{in}^{2}\right)$ and settled to $10.3 \mathrm{MPa}\left(1500 \mathrm{lb} / \mathrm{in}^{2}\right)$. Ten days after this pressurization, we pumped about $6.7 \mathrm{~L}(2 \mathrm{gal})$ of dyed water into each pipe to mark the fractures.

Mineback showed that three of these 6.7-kbar tensile strength pipes had broken and that pressurization had occurred at either the breaks or at locsened pipe couplings (apparently caused by the detonation) at the grouttuff interface. Figure 34 show the cavities at the end 8 of the pipes (the designed fracture points), the actual fracture locations, the charge center, and the dyed fracture pattern observed on mineback. Most likely the fractures close to the pressurization points were caused by the nitrogen pumping 2.5 to $3 \mathrm{hr}$ after the event. The fractures extendi:g into the grout steming were probably caused by the pressure of the dyed water. Most of the fractures were vertical. FPI showed a fracture in tuff at an angle of $60^{\circ}$ to a line running radially from the charge center to the pressurization point. When the fracture reaches the grout steming, it turns and crosses the stemming at $90^{\circ}$ to the axis of the drift. FP2 was pressurized at a break in the pipe at the grout-tuff interface.

A $30-\mathrm{cm}(1-\mathrm{ft})$ fracture extends into the tuff at an angle of $56^{\circ}$; several Eractures extend into the grout and proceed at $90^{\circ}$ to the axis of the stemmed drift. The pressurization point for FP3 was also at the tuffgrout interface. The fracture extending into the tuff shows an angle of $132^{\circ}$; the fracture into the grout shows the aame azimuth but eventually turns and becomes parallel with the other fractures in the grout. Two directions of fractures are noted at the preasurization point for FP4. 
A short $15-\mathrm{cm}(0.5-\mathrm{ft}$ ? fracture is aligned with a radial to the charge center. The second fracture is at $124^{\circ}$ to the radial line and extendo about $30 \mathrm{~cm}(1 \mathrm{ft})$ into the tuff. This fracture extends in the other direction, enters the grout, and rurns parallel to the other grout fractures. Table 5 ammarizes the data on these fractures.

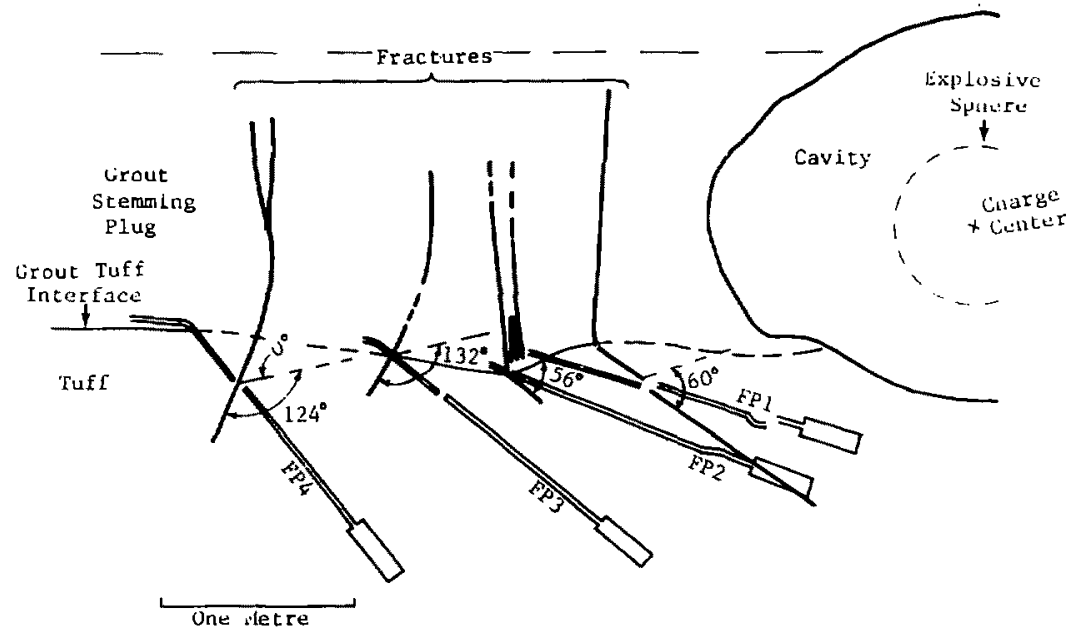

Figure 34. Locations of Pootshot Nitrogen and Water Fractures

Table 5

Fracture Pipe Data

\begin{tabular}{|c|c|c|c|c|c|}
\hline \multirow[b]{2}{*}{ Pipe } & \multirow[b]{2}{*}{$\begin{array}{c}\text { Radial } \\
\text { Distance }(\mathrm{cD}) \\
\end{array}$} & \multicolumn{2}{|c|}{$\begin{array}{r}\text { Breakdown } \\
\text { Pregsure } \\
\end{array}$} & \multirow[b]{2}{*}{ Location } & \multirow[b]{2}{*}{$\begin{array}{l}\text { Fracture } \\
\left.\text { Angle( }{ }^{\circ}\right)\end{array}$} \\
\hline & & $\underline{M P a}$ & $1 b / 2 n^{2}$ & & \\
\hline FPI & 189 & 30.3 & 4390 & Tuff & 60 \\
\hline FP2 & 250 & 15.0 & 2180 & Interface & 56 \\
\hline FP3 & 305 & 19.3 & 2800 & Interface & 132 \\
\hline FP4 & 387 & 14.1 & 2040 & Grout & $0 / 124$ \\
\hline
\end{tabular}


We have observed:

- Breakdowt pressures that decrease approximately with distance from the charge center (the exception is FP3)

- Nearly vertical fractures

- Fractures in grout that differ in orientation from fractures in tuff

- Ore fracture (FP4) that is aligned with a radial leading from the charge center

We believe that the pressure breakdow values show the existence and approximate dependence of the residual stress field on distance for hydraulic fracturing work, about 50 metres away, showed breakdown values in the range of 7.6 to $10.3 \mathrm{MPa}\left(1100\right.$ to $\left.15001 \mathrm{~b} / \mathrm{in}^{2}\right)$. A $0^{\circ}$ fracture at FP' implies that the radial residual gtress was larger than the hoop residual stress at $387 \mathrm{~cm}$ from the charge center. The $60^{*}$ fracture in tuff at FPl (189 cm) suggeats that the residual hoop stress at this iocation is larg?r chan the residual radial stress. The parallel dyed fractures crossing the grout column were interpreted by the geologist conducting the mineback as "training along a series of pre-existing, ie, detonation-related, fractures."

Although chis fracture pipe experiment did not provide quantitative residual stregg values, it did show the existence of the residual otreas Eipld, a rough idea of the decay of the field with distance, and an indication of the amplitude, of the hoop compared to that of the radial stresa at two locationg.

\section{Mineback}

Mineback in PUFF TOO proceeded in the tuff on the right (south) sile of the grout steming plug. We cxcavated a drift with a continuous miner to about $3 \mathrm{~m}(10 \mathrm{ft})$ beyond the charge center. Hand excavation exposed gages and pipes in the grout plug. Carbon monoxide was encountered along the grout-tuff interface. About $6 \mathrm{~m}(20 \mathrm{ft})$ from the cavity we stopped mining and drilled two holes into the cavity to flugh out the co. All notable details were carefully mapped and photographed; only highlights are included below. 
At $42.43 \mathrm{~m}(135 \mathrm{ft})$ in the wineback drift, we encountered the cavity which was filled with rubble except for a $60-$ to $90-\mathrm{cm}(2-, 0-3-f t)$ open zone at the cop: the roof of the cavicy had collapsed and exposed fresh tuff. When we cleaned out the rubble, we encountered the usual black detonation residue around the sides and on the bottom. Using the reaidue as boundary, we obtained the cavity shape shown in Figure 35 . The cavity is elongated in a $45^{\circ}$ E direction, " has a maximur and a minimun horizontal dimension of about $250 \mathrm{~cm}(8 \mathrm{ft})$ and $200 \mathrm{~cm}(7 \mathrm{ft})$ respectively. Cavity radii toward the grout $p l u g$ are about $20 \%$ larger than those to the tuff. To extract a radius of this cavity, the area of the horizontal plane through the charge center and bounded by the cavity edge was integrated and set equal to $\pi R^{2}$, resulting in an extracted radius of $108.4 \mathrm{~cm}$ ( $3.56 \mathrm{ft}$ ). An average radius was obtained by measuring radii st $20^{\circ}$ increments, arriving at $107.4 \mathrm{~cm}(3.52 \mathrm{ft})$.

Examination of the stemming plug grout at the cavity wall giowed a notable difference from the tuff at the cavity wall. Although a sample of the tuff cauld be biaken by hand, the grout appeared quite solid. To quantify the difference, we cored and tested amples at various diatances from the charge center. There vas poor recovery wimen the soft tuff was cored close to the cavity; apparently a hard inclusion would break up the core. Samples of this ooft tuff have been aubmitted for petrographic examination. Tuff cores at a diatance of 354 and $448 \mathrm{~cm}(11.6$ and $14.7 \mathrm{ft})$ from the charge center showed unconfined crush strengths of 6.83 and $10.1 \mathrm{MPa}$ ( 990 and $14601 \mathrm{~b} / \mathrm{in}^{2}$ ) respectively. A grout sample from the cavity wall, $128 \mathrm{crn}(4.2 \mathrm{ft})$ from the charge center, showed an unconfined crushing strength of $15.8 \mathrm{MPa}\left(2290 \mathrm{Lb} / \mathrm{in}^{2}\right)$ aid one taken at $402 \mathrm{~cm}(13.2 \mathrm{ft})$, showed a value of $25.3 \mathrm{MPa}\left(36 / 0 \mathrm{1b} / \mathrm{in}^{2}\right)$.

\footnotetext{
"This is about the direction of the aaximum horizontal component of the in-situ stress. If in-situ stresses dominated the direction of maximum cavity growth, we would see a cavity turned $90^{\circ}$ from the observed orientation .
} 


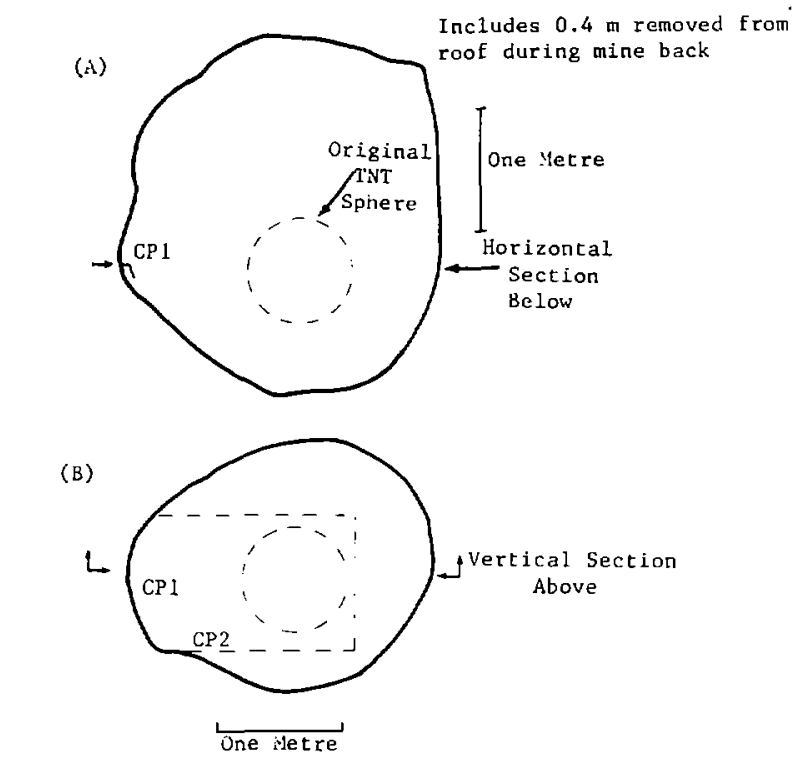

Figure 35. Vertical and Plan Views of Cavity

The tuff next to the cavity had a zone of concentric (onion skin) fractures that was about $60 \mathrm{~cm}(2 \mathrm{ft})$ thick. At the cavity wall, black residue filled or caated about $3 \mathrm{~cm}$ of the concentric fractures. Beyond this onion skin zone, there was another zone of "softer than normal tuff" $100 \mathrm{~cm}(3.4 \mathrm{ft})$ thick. No radial fractures with black residue extended from the cavity walls. Samples of this soft tuff have been submitted for petrographic examination.

Blark residue was observed at several locations well away from the cavity. An approximately radial fracture about $45 \mathrm{~cm}(1.33 \mathrm{ft})$ long was found at $210 \mathrm{~cm}(6.85 \mathrm{ft})$ from the charge center, near the end of FP3. No connection of this black fracture with the cavity was found. On the side away from the stemming plug, about $300 \mathrm{~cm}(10.2 \mathrm{ft})$ from the charge center, Dlack residue was found on a core sample. No excavation was 
performed to determine the source of the black residue. Near the collar of gage hole $\mathrm{E}$, about $600 \mathrm{~cm}(20.4 \mathrm{ft})$ from the charge center, there was $a$ patch, about $90 \mathrm{~cm}(2.9 \mathrm{ft})$ long $\times 60 \mathrm{~cm}(1.9 \mathrm{ft})$ high, of thin black reaidue in horizontal atreaks at the grout-tuff interface.

We also encountered two slickenside surfaces, the main one (Figure 36) in tuff, approximately parallel to the grout-tuff interface. This surface started at $165 \mathrm{~cm}$ from the charge center $(5.4 \mathrm{ft}$ or 1.5 cavity radii) and extended to $463 \mathrm{~cm}(15.2 \mathrm{ft}$ or $4.3 \mathrm{cavity}$ radii). The observed vertical excent was $90 \mathrm{~cm}(2.9 \mathrm{ft})$ at FPl and $30 \mathrm{~cm}(1 \mathrm{ft})$ at FP3. The approximately vertical surface had sheared three of the FPs when it moved. The time of this movement is suggested by the records from gage IEYG in hole $E$, whose three gage elements showed an abrupt electrical failure at $5.5 \mathrm{ma}$. If se were to extend this fracture vertically, we would find that it would, indeed, encounter hole $E$.

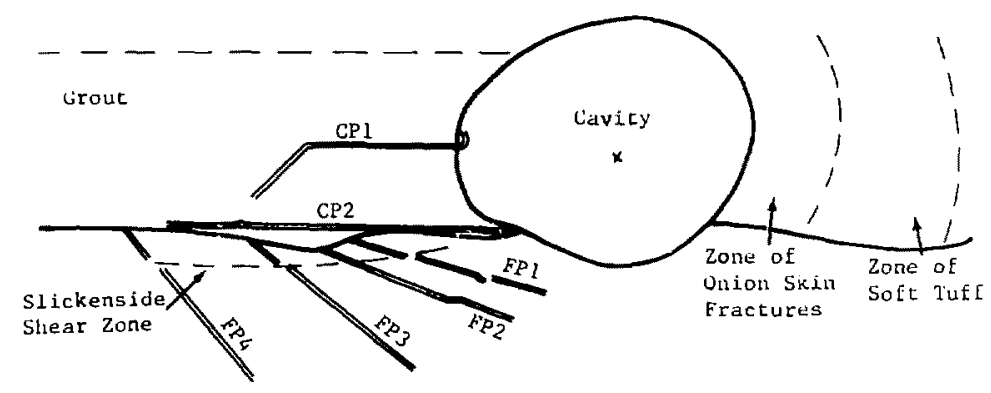

Figure 36. Plan View of Mineback Showing Zones of Shear Surface, Onion Skin Fractures, and Soft Tuff

Near the end of the FPl, there was another slickenside passing through broken and offset pipe. This ourface was about $60 \mathrm{~cm}$ ( $2 \mathrm{ft}$ ) lang and approximately parallel to the grout-tuff interface.

These two shear surfaces show that the grout $\mathrm{fug}$ and some adjoining tuff moved differentially to the rest of the tuff. The emplacemrnt drift 
had bern open for about 8 months before grouting and some destressing had undoubtedly occurred in the tuff. This destressing is comon in the tunnel complex and often causes open fractures parallel to the tunnel surface, (The walls of the drift had been sprayed with a sealant to mininize water loss.)

Mineback on PUFF TOO was useful because it enabled us to do the Esllowing :

- Examine the cavity

- Obtain aetails on the post-event fracture presoure experiment

- Obtain details on the cavity pressure pipes

- Recover gages to examine then for failure

- Sample the stressed tuff and grout

- Examine some evidence of differential motion in the tuff parallel to the emplacement drift 
APPENRIX A

Gage Calibration

To measure residual scress, we need gages that survive the dynamic ef cects of the detonation and retain a linear, or recoverable, calibration. This requirement eliminates gages that show a variable hysteresis effect or those whose sensing element breaks under nonhydrogtatic loading. Survivability of electrical leads in the divergent flow rield is probably the main concern. In designing the PUFF roo experiment, we chose state-afthe-art gages that offered the posibility of measuring residual stress.

Previous, amall-scale, work at Sandia's Coyote Test Field had shown that fluid aupled lithium niobate crystal gages survived to about 6 kbar. Several of these were inatalled in PUFF TOo to explore their survivability at high stresses under field conditions. We also installed ytterbium gages which have been popular during the lagt $10 \mathrm{yr}$, principally because of their large piezoresistive coefficient (100\% resistance change at 10 kbar) and survivability at high otressea. Calibration experiments using gas gun techniques to produce one-dimension strain on this material, however, show a hyoceresis effect. ${ }^{3}$ Hydrostatic loading of ytterbium shows no hysteresia; therefore, by coupling ytterbium to the geologic host with fluid offerg the posibility of measuring residual atregs. This fluid-coupled ytterbium gage has also been tested at the coyote Teat Field. On PUFr TOO we used several of these fluid-coupled gages, along with several conventional ytterbium and lithium niobate gages. We also installed three examples of prototype triaxial stress gages.

Hork with piezoelectric, chium niobate crystalline material is relatively new because agtig, ctory oingle crystalg have been available only for the past $15 \mathrm{yr}$. An early application of these crystals was in high-temperature ultrasonico; their curie temperature is significantly higher than other piezoelectric materiala. Graham showed that lithium 
niobate was buitable for time-resolution measurements of impact loads, for example, in gas gun experiments. ${ }^{4}$ He also oubjected the material to hydrostatic loading of up to $20 \mathrm{kbar}$ and found excellent reproducibility, a piezoelectric constant of $6.31 \mathrm{pC} / \mathrm{N}$, and minor nonlinearity. ${ }^{5}$ Reed adapted this transducer material to a variety of charge-mode gageo for measuring free-field stress. In one design, a z-cut crystal is embedded between two thin pieces of epoxy-Fiberglas TM (circuit) board; solid epoxy couples the crystal to the glass board. This solid-coupled (PHA) gage is shaped like a paddle with a width of about $7 \mathrm{~cm}$ and a length of about $15 \mathrm{~cm}$. This package has been hydrostatically loaded and shows the same coefficient observed for the bare crystal but has one limitation: failure at high streas levelo. This is believed to be caused by nonhydrostatic loading of the relatively britcle crystal material. Once fractured, lithium niobate shows enhanced output.

In the fluid-coupled adaptation (PFA) ${ }^{6}$ of the lithium niobate paddle, the crystal is held lightly between the pieces of circuit board by a porous foam. The coupljig fluid, silicon oil DC7lo, was chosen for its low compressibility property and its high electrical resigtivity. The difference in compressibility oetween the circuit board, the fluid, and the host material causes fluid-coupled gages to register a stress that is different from free-field stress when they are subjected to stress levels below the yields of the materials involved.

An examination of the =oss-axis piezoelectric strain coefficients $\left(d_{i j}\right)$ for lithium niobate ${ }^{4,6}$ showa that several are cuite large, and the z-cut crystal may show significant cross-axis sensitivity when subjected to a triaxial stress field. Using the fluid-coupled crystal does not totally rer live the matcer becauae the reaponse of the gage package which contains the fluid-coupled crystal has not been fully explored in a triaxial stress field. Work on this problem is in progress.?

The data from lithium niobate gages in the PUFF TOO experiment were reduced by using $d_{h}=6.31 \mathrm{pC} / \mathrm{N}$ as the piezoelectric strain coefficient. 
The other principal gages which we fielded in PUFF TOO uged ytterbium foil grids. One-dimension strain calibration has been performed on these gages by Ginsberg with gas gun experiments. ${ }^{3}$ This calibration, appropriate to fast risetime loading, is

$$
\sigma(\mathrm{kb})=1.082\left[1-\exp -20.8 \frac{\Delta R}{K_{0}}\right]+9.168 \frac{\Delta R}{R_{0}} .
$$

Under multidimenaional strain loading and below yielding of hast materials, one must account for the triaxial srate of atress.

When used in one-dimengional otress compression, an ytterbium grid shows a hysteregis effect which ray obscure a measurement of residual stress. Again we have used a fluid-coupling gcheme to elininate this effect. Lilly and Stephens showed that, under hydrostatic loading, ytterbium unloads along itg loading path. ${ }^{8}$ The coefficient is:

$$
\sigma(k b)=2.15\left[\sqrt{38+93.2\left(\Delta R / R_{o}\right)}-6.16\right],
$$

where $\Delta R / R_{0}$ ig $\theta t r e s s-i n d u c e d$ resistance change divided by the original gage resiatance. As with any fluid-coupled gage, we have the potential effects of under-regiatration of the gage because of the mismatch of compressibility properties between the fluid, the package, and the host. This effect is a opecific case of the gage package reaponding to the triaxial state of atress. Dats from fluid-coupled ytterbiun gages in PUFF TOO were reduced by using the Lilly and Stepheng hydrostatic calibrations, but without correction for regigtration effect. Data from the solidcoupled ytterbium grids were reduced with Ginsberg's one-dimension strain calibration.

In the early days of stress measurements, amplitudes of interest produced hydrostatic presoure because atresses were well above yielding of host and gage package materials; therefore, the triaxial atress state problems were minimal. In loading waterials at and below the l-kbar peak amplitude, significant nonhydrostatic atresses are generated. Therefore, 
ane-dimension strain and hydrotatic gage calibratione ang not be appropriate. We must exomine the response of the gages to this triaxial state of stress; perhaps even new gage configurations may be required. Current application for these triaxial atate-of-stres meaureaents is to decerinine the stress wave loading, unloading, and subsequent fracturing of geologic materials containing fosail fuel. To undersand the phenomenology sf rock fracture and to evaluate compu*-: code codeling of the processes, triaxial atate-of-stress measurements mut be rigorouly pursued. 


\section{APPENDIX 8}

Computer Code Calculation

Before we fielded puff roo, R. C. Basa performed a computer code calculation of the detonation of $454 \mathrm{~kg}(1000 \mathrm{lb})$ of high explosive in wet tuff. Of interest were details useful for planning the experiment, for example, the radial dependence of the residual stress field. For this purpose, coarse edits (100m- intervals) vere obtained through the 10-ms duration of the calculation. Zone cizes were large and associated "smearing" over zones were not optimized for postevent comparison with experimental results. A one-dimension Lagrangian code called CHART D, written by Sam Thompson, was used." In this calculation an elasticperfect plastic mode: was used with an elastic 1 imit of 1.0 kbar and a Poisson ratio of 0,31 . These values were chosen on the basis of previous experience and parameter studies and are generally repregentative of wet $t \cup f f$.

Figure B-I shows stress vs distance at 10.0 ms. The small amplitude humps near the right edge $(1400$ to $2000 \mathrm{~cm})$ are the outward propagating dynamic effects. The sharp rise at $79.4 \mathrm{~cm}$ is the edge of the cavity and the constant amplitude preceding the rise is the cavity pressure (0.55 kbar). From the cavity edge, we see that the hoop stress riges sharply to about 1.2 kbar, decayg to near zero at $155 \mathrm{~cm}$, shows a second rise, decreases to below the zero level and rises to the tail of the dynamic effect. Two coments are appropriate here: a hydrostatic presoure of 50-kbar preload was used, and no feacture was alloued in the calculation. Beginning at the cavity edge, the radial stress shows a rise to a rounded peak of $0.75 \mathrm{kbar}$ and a decay to $0.1 \mathrm{kbar}$ before we see the tail of the dynomic effects. The third curve shows mean atress, $\bar{\sigma}=(1 / 3)$ $\left(\bar{\sigma}_{r}+2 \sigma_{\theta}\right)$. Through the time regine of 6 to $10 \mathrm{mg}$ the rangemplitude "snapshots," such as shown in Figure B-1, ahow little change in the otress 
fields near the cavity; we believe that the curvea are the residual atreso field.
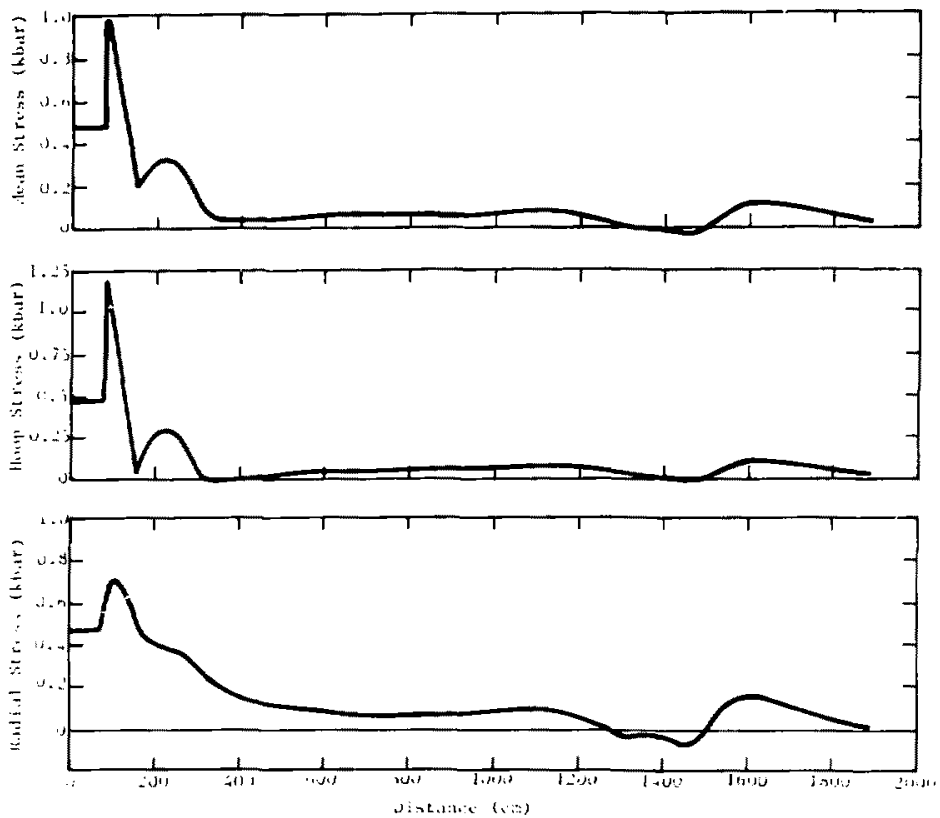

Figure B-1. CHART D Calculation - Stress vs Distance at $10 \mathrm{~ms}$

Field measurements showed a digtorted cavity; a cavity radius extracted from th ? cross-sectional area of a horizontal plane passing through the charge center and intersecting the cavity wall yields a value of $108 \mathrm{~cm}$ (compare with the calculated value of $79.4 \mathrm{~cm}$ ). Field measurements of cavity pressures are still in their infancy; this is a difficult quanticy to measure and only two values, $0.52 \mathrm{kbar}$ and $0.21 \mathrm{kbar}$ were obtained. Current experience doea not allow us to give more weight to one or the other; however, the larger value is close to the calculaced value of 0.55 kbar. 
Figure B-2 shows the waveform measured in the experiment by gage 6AYFC. The figure also plats 100- $\mu_{a}$ interval data (mean stress and radial stress) obtained from the edits of the calculation at the appropriate distance. Closer spaced edits would have show a faster rise time and a higher peak stress.

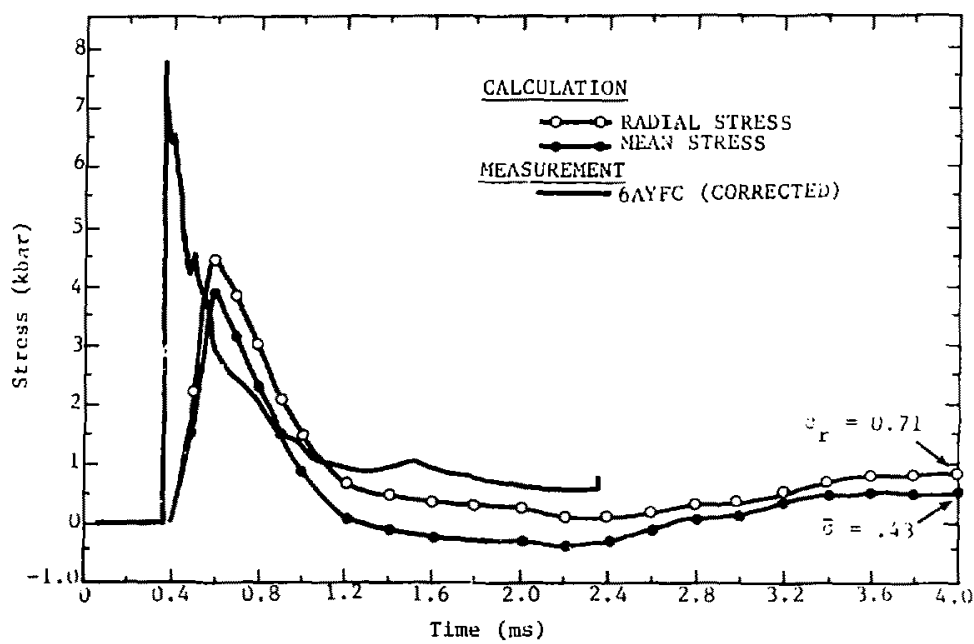

Figure B-2, Calculated Radial and Mean Stress and Measured Stress at $133 \mathrm{~cm}$

Figure B-3 ahows aimilar data for the 2-kbar nominal level. Beyond $5 \mathrm{mo}$, we see close agreement between the measured residual atress and the calculated mean and radial atress. Figure B-4 sho. 3 field data from gage IDLFC compared with the calculation. Again we see a notable difference in the 2 to $4-m s$ unloading behavior. The average of the residual stress for all the 1-kbar gages is $0.22 \mathrm{kbar}$, which agrees fairly well with the calculated $0.16-k b a r$ radial stress. 


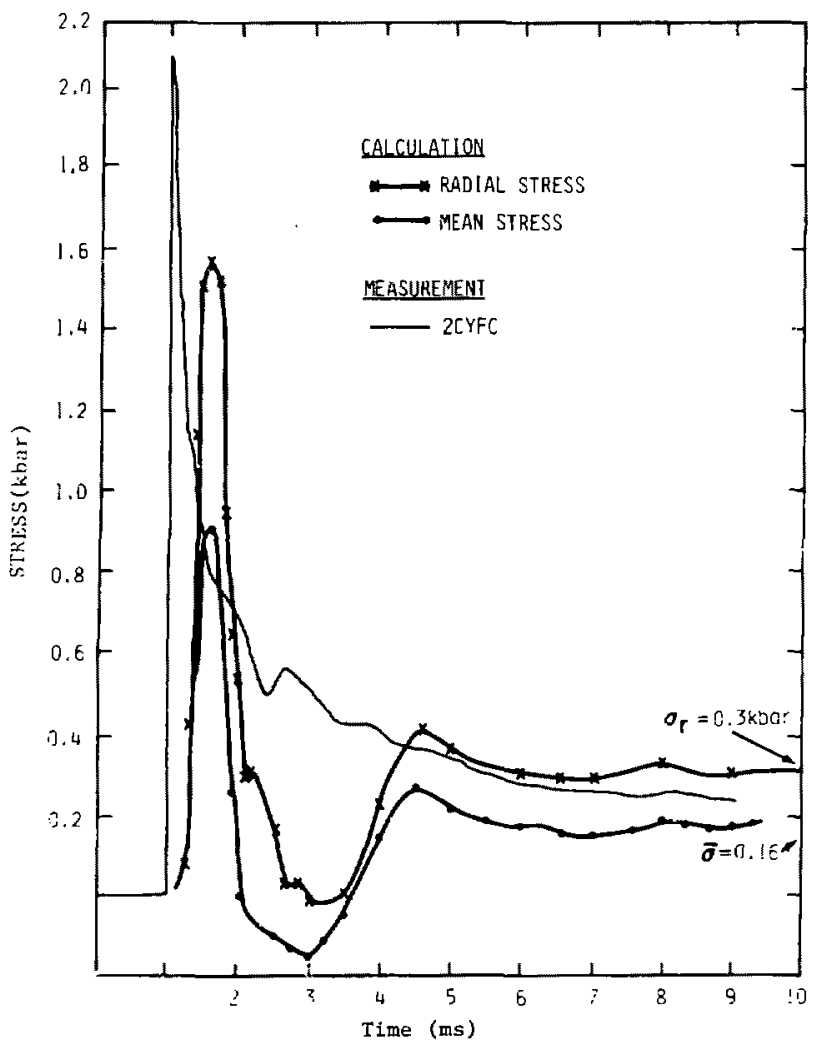

Figure B-3. Calculated and Measured Stresseg va Time at $290 \mathrm{~cm}$ 


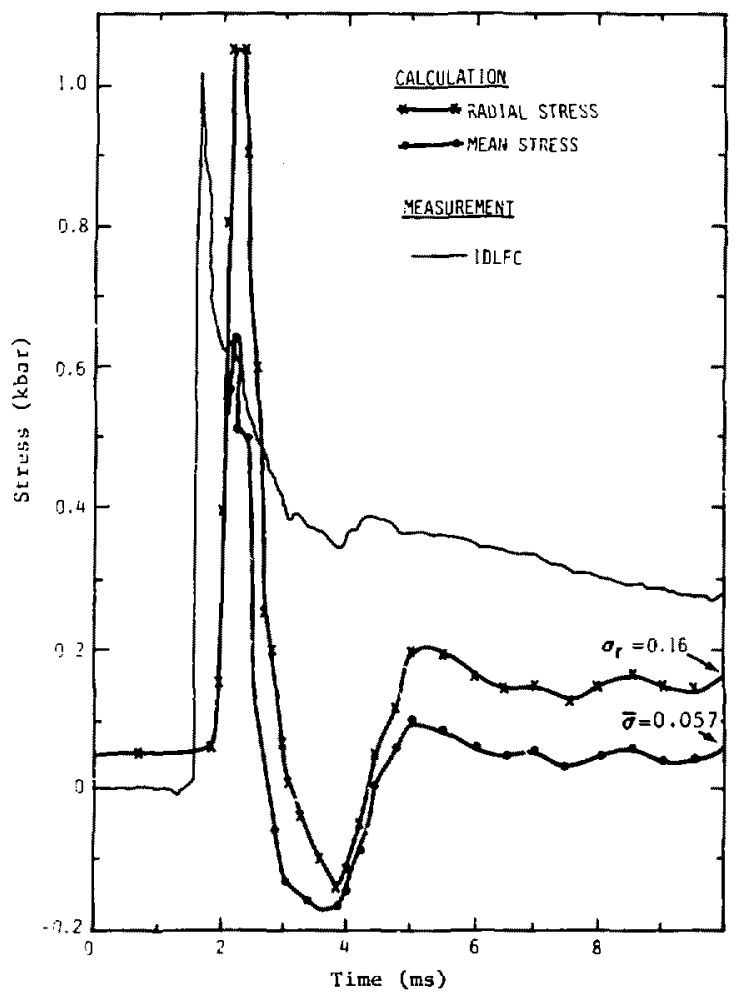

Figure B-4. Calculated and Measured Stresses vs Time at $419 \mathrm{~cm}$ 
Except for a major dip in the unloading portion of the wavefoim, the calculated waveforms show reasonable agreement with experimental measurements. However, measured and calculated cavity sizes disagree. This diaagreenent probably reflects the use of a material strength value in the calculation that was too high.*

*Poatevent calculational work with a material model in wich the strength value decreases following atress wave loading shows a larger cavity radius and an eliqination of the tensile phase. 


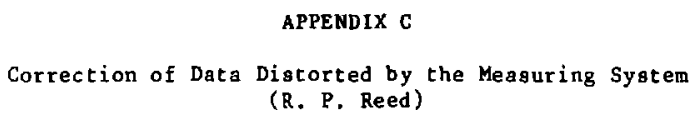

The special constant-turrent power supply used for aignal conditioning the ytterbium gages is designed to respond to the rapidly-changing stresses in explosive experiments. The measurement reqires that we abgerve a relatively gmall transient aignal superimposed on a relatively large dc level. Special signal conditioning elminates the dc level and thus improves the resolution of the recording. The intended step-response of the power supply approximates a decaying exponential function of greater than a 20-a time constant. The transient signal distortion cauaed by this normal, long-time constant on pulses of less than 10 ms is much less than $0.1 \%$.

After the PUFF TOO test, we found several channela of signal conditioning that had resiatora with a value that was too low. These values reaulted in a decay-time constint of 1 ess than $2 \mathrm{~ms}$. As a result the corresponding transfer function grossly distorted the signals recorded on those channels. Fortunately, after the shot, we could measure the actual transfer function to a good approximation and make data corrections. The data we corrected had been recorded on gages IYGL, IEYGI, IEYG2, and GAYFC.

Figure C-1 illugtrates that data recorded for gage 6AYFC, a fluidcoupled ytterbium gage. The record indicates, that stress returned to zero at $1.2 \mathrm{~ms}$ after the pulse arrived and then became tensile at $1.62 \mathrm{~ms}$. Both indications are incorrect. The underghoot is a consequence of the response by the signal conditioning ystem. The measured unit step response of the system is shown in Figure $\mathrm{C}-2$. The actual response was anslytically repreaented by the exponential function 


$$
U(t)=1781\left(e^{-\frac{t}{1.7746}}\right)\left(1-0.1512 e^{-\frac{t}{0.2857}}\right)
$$

This characteristic was used to calculate the oystem input (forcing iunction) from the distorted recorded output. The corrected result is shown in Figure $\mathrm{C}-3$.

Correcting the data discottion affected the peak amplitude by only $0.04 \%(0,003 \mathrm{kbar})$ but the 1 ate-time regidus 1 stregs was corrected significantly to $0.58 \pm 0.03 \mathrm{kbar}$ compressive instead of $0.30 \mathrm{kbar}$ tensile. The correction is crucial becsuse a msjor abjective of PUFF TOO was to measure residual gtregs.

The unfold algorithm used for correction is the same simple timedomain deconvolution long used for correcting data from quertz shockstress gages with a shorted guard-ring. The entire unfolding algorithm, as implemented in the GENFOLD signal analysis code ( $R$. $P$. Reed), is as fol lows:

PERFORM UNFOLDINC BY DIRECT INVERSION OF DUHAMEL SUMMATION.

$\operatorname{RESULT}(1)=\operatorname{SUBJ}(1) / U(1)$

DO $1070 \mathrm{~N}=2$, NSTEPS

$$
\operatorname{RESULT}(\mathrm{N})=\mathrm{S} 1 \mathrm{BJ}(\mathrm{N})
$$

$\mathrm{NM} \mathrm{l}=\mathrm{N}-\mathrm{I}$

DO $1060 M=1, N M 1$

$1060 \operatorname{RESULT}(N)=\operatorname{RESULT}(N)-(U(N-M+1)-U(N-M))+\operatorname{RESULT}(M)$

$1070 \quad \operatorname{RESULT}(\mathrm{N})=\operatorname{RESULT}(\mathrm{N}) / \mathrm{U}(1)$ 


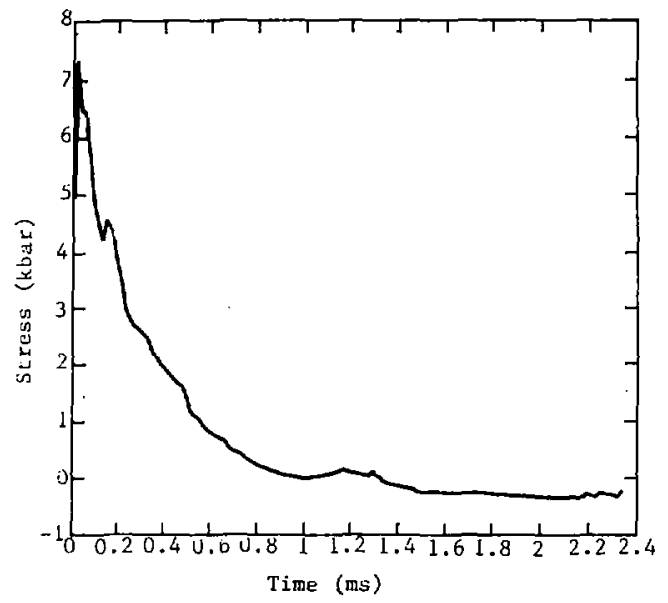

Figure C-l. Data from Gage 6AYFC as Recorded (Distorted by Short Time Constant)

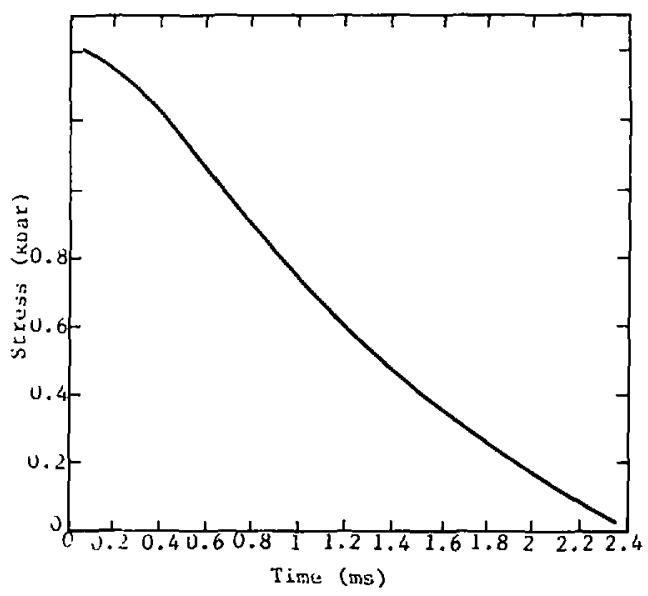

Figure C-2. Unit Step Response of Signal Conditioning 


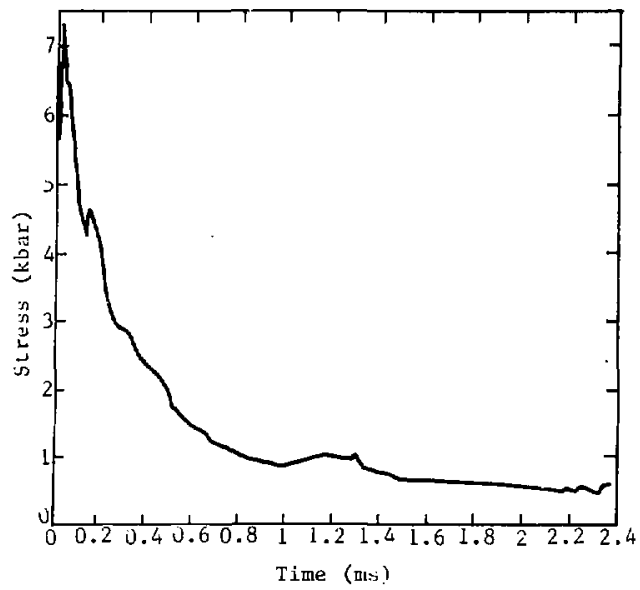

Figure C-3. Data from Gage 6AYFC Corrected for Transient Distortion 


\section{References}

$l_{R}$. C. Bass to author; Oral Communication

${ }^{2} \mathrm{~J}$. T. Rogenberg, Development of Piezoresigtive Transducerg to Measure Stress Time Output of Small Detonators (Stanford, CA: Stanford Research Institute, Mar 1973). Project PYU1283.

$3 \mathrm{M}$. J. Ginaberg et al, Effects of Stregs on the Electrical Registance of Ytterbium and Calibrated Ytterbium Stress Transducers, DNA3577F (Stanford CA: Stanford Research Ingtitute, Aug 1973).

${ }^{4}$ R. A. Graham, "Lithium Niobate Stress Tranaducers," in Selected Papers on Piezoelectricity and Impulsive 'Pressure' Measurements, SAND78-1911, ed R. A. Graham and R. P. Reed (Alouquerque: Sandia Laboratories, Dec 1978).

${ }^{5}$ R. A. Graham, "Preasure Dependence of the Piezoelectronic Polarization of $\mathrm{LiNBO}_{3}$ and $\mathrm{LiTaO}_{3}$. Ferroelectrics," in Vol 10 of Selected Papers on Piezoelectricity and Impulsive 'Pressure' Measurements, SAND78-1911, ed R. A. Graham and R. P. Reed (Albuquerque: Sandia Laboratories, Dec 1978). Written in 1976.

${ }^{6}$ P. P. Reed, "A System for Measurement of Free-Field Stress Waves Using Lithium Niobate Piezoelectric Transducers," in Selected Papers on Piezoelectricity and Impulsive 'Pregsure' Measurements, SAND78-1911, ed R. A. Graham and R. P. Reed (Albuquerque: Sandia Laboratorieg, Dec 1978). Presented at NINTH Transducer Workshop, Fort Walton Eeach, Florida.

${ }^{\prime} R$. P. Reed, "Triaxial Measurements of Stress Waves in t'ie FreeField," Unpublished paper presented at the Range Commander's councils Tenth Transducer Workshop, Colorado Springa, June 1979. Copies available from the author at Sandia Laboratories.

${ }^{8}$ E. M. Jilley and D. R. Stephens, Electrical Resistance of Ytterbium as a Function of Temperature and Pressure, UCRL-51006, TID-4500, UC-4 (Lawrence, CA: Lawrence Radiation Laboratory, Nd).

${ }^{9} \mathrm{~S}$. L. Thompson, Improvements in the Chart D Radiation-Hydrodynamic Code, SC-RR-70-28 (Albuquerque: Sandia Laboratories, Jan 1970). 